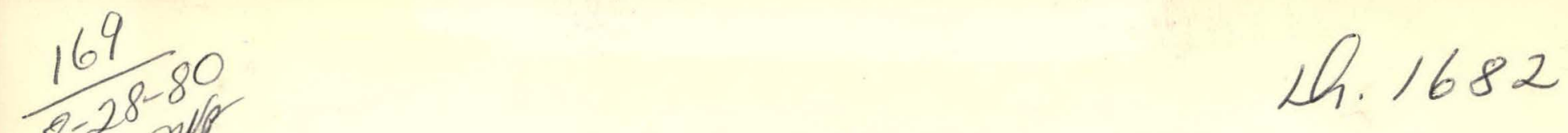

ORNL/TM-7384

OAK

RIDGE

NATIONAL

LABORATORY

\title{
User's Guide for the Revised SPEC-4 Neutron Spectrum Unfolding Code
}

\section{UNION \\ CARBIDE}

\author{
J. O. Johnson \\ D. T. Ingersoll
}

\section{OPERATED BY}

UNION CARBIDE CORPORATION FOR THE UNITED STATES DEPARTMENT OF ENERGY 


\section{DISCLAIMER}

This report was prepared as an account of work sponsored by an agency of the United States Government. Neither the United States Government nor any agency Thereof, nor any of their employees, makes any warranty, express or implied, or assumes any legal liability or responsibility for the accuracy, completeness, or usefulness of any information, apparatus, product, or process disclosed, or represents that its use would not infringe privately owned rights. Reference herein to any specific commercial product, process, or service by trade name, trademark, manufacturer, or otherwise does not necessarily constitute or imply its endorsement, recommendation, or favoring by the United States Government or any agency thereof. The views and opinions of authors expressed herein do not necessarily state or reflect those of the United States Government or any agency thereof. 


\section{DISCLAIMER}

Portions of this document may be illegible in electronic image products. Images are produced from the best available original document. 
Printed in the United States of America. Available from National Technical Information Service

U.S. Department of Commerce

5285 Port Royal Road, Springfield, Virginia 22161

NTIS price codes-Printed Copy: A05; Microfiche A01

This report was prepared as an account of work sponsored by an agency of the United States Government. Neither the United States Government nor any agency thereof, nor any of their employees, makes any warranty, express or implied, or assumes any legal liability or responsibility for the accuracy, completeness, or usefulness of any information, apparatus, product, or process disclosed, or represents that its use would not infringe privately owned rights. Reference herein to any specific commercial product, process, or service by trade name, trademark, manufacturer, or otherwise, does not necessarily constitute or imply its endorsement, recommendation, or favoring by the United States Government or any agenry therenf The views and opinions of authors expressed herein do not necessarily state or reflest those of the United States Government or any agency thereof. 


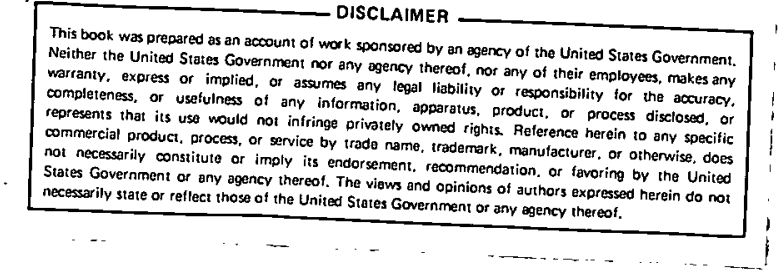

\section{GRNL/TM-7384 \\ Distribution Category UC-77 \\ Gas Cooled Reactor Tech.}

Contract No. W-7405-eng-26

Engineering Physics Division

USER'S GUIDE FOR THE REVISED SPEC-4 NEUTRON SPECTRUM UNFOLDING CODE

J. 0. Johnson*

D. T. Ingersoll

Date Published - August 1980

NOTICE. This document contains information of a preliminary nature. It is subject to revision or correction and therefore does not represent a final report.

*University of Tennessee, Department of Nuclear Engineering, Knoxville, Tennessee 37916

OAK RIDGE NATIONAL LABORATORY

operated by

UNION CARBIDE CORPORATION

for the

DEPARTMENT OF ENERGY 
THIS PAGE

\section{WAS INTENTIONALLY \\ LEFT BLANK}


TABLE OF CONTENTS

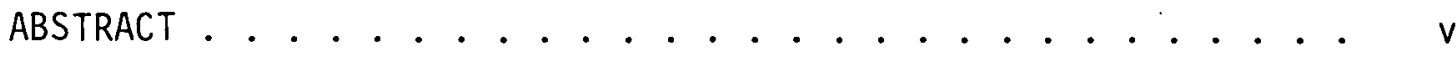

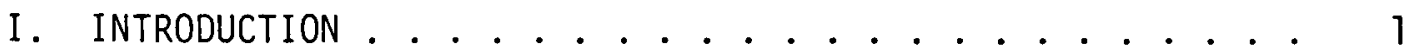

A. Background ............... . . 1

B. Method of Solution ............ . .

C. Application to the TSF Experiments . . . . . . . 3

D. Recent Modifications ............. 3

II. INPUT REQUIREMENTS .................... 5

A. Card Descriptions.............. 5

B. Data Notes............... 8

III. JCL REQUIREMENTS ................. 13

IV. OUTPUT FROM SPEC-4 . . . . . . . . . . . 17

V. OPERATING EXPERIENCE AND RECOMMENDATIONS ....... 19

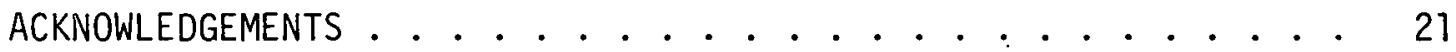

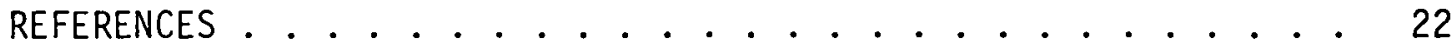

APPENDIX A. A BRIEF GUIDE TO THE SPEC-4 UNFOLDING CODE. . . . A-1 APPENDIX B. LISTING OF THE RAWDAT PROGRAM . . . . . . B B-1 APPENDIX C. A SAMPLE PROBLEM FOR SPEC-4 .......... C C-1 APPENDIX D. LISTING OF THE BENJPLT PROGRAM. . . . . . . . D-1 
THIS PAGE

\section{WAS INTENTIONALLY \\ LEFT BLANK}


The SPEC-4 computer code was developed in the United Kingdom to solve the spectrum unfolding problem for spherical gas-filled proton-recoil neutron spectrometers. This report describes the ORNL version of SPEC-4 which has been applied to the analysis of data from the Tower Shielding Facility. Recent modifications are described which largely pertain to the graphical output routines. In addition, the input requirements are presented in considerable detail including suggestions and recommendations based on actual operating experience. Finaliy, auxiliary programs are discussed which can aid the SPEC-4 user. 


\section{INTRODUCTION}

\section{A. Background}

The SPEC-4 computer code was developed by P. W. Benjamin, C. D. Kemshall, and A. Brickstock at the Atomic Weapons Research Establishment (AWRE), United Kingdom, to solve the spectrum unfolding problem for spherical gas-filled proton-recoil neutron spectrometers. The original report ${ }^{1}$ and source program (consisting of the SPEC-4 master routine and subroutines SPEC2S, SNIDOW, and VSMTH) were combined with other related reports and packaged for distribution by the Radiation Shielding Information Center (RSIC) ${ }^{2}$. Like all good codes, however, SPEC-4 was promptly modified for local use at ORNL - in this case, by R. M. Freestone. His motivation was to adapt the RSIC code to analyze gas proton-recoil measurements made at the Tower Shielding Facility (TSF), and to add special editing and graphical output routines. The purpose of this report is to provide formal documentation of the evolution of SPEC-4 at ORNL, and to detail input requirements. Also, helpful guidelines based on accumulated experience are presented which should aid the user in the selection of input parameters and interpretation of results.

\section{B. Method of Solution}

An effective method for measuring neutron spectra in a low-power fast reactor is the measurement of the energy distribution of recoiled protons in a gas-filled proportional counter. Combined with a detailed description of the detector response, the measured proton-recoil data can be numerically translated to yield the incident neutron energy distribution. The primary purpose of the SPEC-4 code is to determine detector responses by calculating proton-recoil energy distributions from monoenergetic neutrons, and then to unfold measured proton-recoil spectra to yield the corresponding continuous neutron energy spectra. This method has been in use for a number of years to measure neutron spectra in the energy range $1 \mathrm{keV}$ to $3 \mathrm{Mev}$. The required input data includes the measured proton-recoil 
spectrum, the relevant counter parameters, and an estimate of the neutron spectrum above the highest measured energy.

The basis for the analytic method used by SPEC-4 to calculate response functions is derived from the fact that monoenergetic incident neutrons produce recoiled protons with a retangular-shaped energy distribution. The presence of the detector walls, and the geometric effects of charge collection cause the idealized rectangular distribution to be distorted; however, for spherical detectors, these distortions can be calculated dimust exactiy. Unce the detector response has been calculated, the measured data can be unfolded using conventional differentiation techniques to yield an estimate of the incident neutron flux distribution. Because of the near-rectangular distribution of proton recoils, even neutrons with energies greater than the upper energy limit of the gas counter will induce some proton recoils within the counter and hence produce an undesirable signal. For this reason, SPEC-4 requires an estimate of the neutron flux above the upper limit of the counter in order to remove the corresponding "background" portion of the measured data. The basic steps executed by SPEC-4 are:

(a) Calculate the proton-recoil distribution due to ncutrons above the highest measured energy. The high-energy flux may be estimated, calculated, or measured (e.g., with an NE-213 spectrometer),

(b) Calculate a matrix of proton-recoil response functions corresponding to neutron energies within the measurable limits of the detector,

(c) Subtract the "background" data calculated in (a) from the measured data,

(d) Unfold the net proton-recoil spectrum calculated in (c) using the response matrix calculated in (b).

Since both steps (a) and (b) must account for the response distortions due to the detector geometry, a reliable solution can be expected from SPEC-4 only for detectors having the same geometry, i.e., spherical. 


\section{Application to the TSF Experiments}

The following discussion is a general description of the application of SPEC-4 to the TSF experiments. An internal correspondence written by R. M. Freestone (included as Appendix A) was used as a reference.

The data which SPEC-4 is designed to unfold are pulse height distributions obtained with spherical, gas-filled, proton recoil proportional counters, called Benjamin counters. At the present time, three counters are used at the TSF (SP-28, SP-26, and SP-25), each with a radius of $2.32 \mathrm{~cm}$. The $\mathrm{SP}-28$ counter is filled with pure hydrogen gas to a pressure of 10 atmospheres and is used to measure neutrons in an energy range from about 0.200 to $1.5 \mathrm{MeV}$. The SP-26 counter is filled with pure hydrogen gas to a pressure of 3 atmospheres and is used for neutrons in an energy range from 0.100 to $0.300 \mathrm{MeV}$. The SP-25 detector is filled with pure hydrogen gas to a pressure of one atmosphere and is used for neutrons between $40 \mathrm{keV}$ and $0.200 \mathrm{MeV}$. It is possible to measure to lower energies, but electronic discrimination against gamma-rays must be employed.

Normaliy, a set of data from the TSF consists of a foreground and a background run for each of the three detectors. The data is acquired using a conventional 255-channel pulse-height analyzer, and then recorded in tabulated form and also punched on paper tape. The paper tape is submitted to the ORELA PDP-10 computer by TSF personnel to obtain a deck of punched data cards. These cards along with a "fact sheet" are delivered to the data analyst for subsequent unfolding. The "fact sheet" contains the normalization and calibration data needed as input for the SPEC-4 code. The analyst then has the responsibility of producing the unfolded spectrum in three formats: tabular listing, graphical plot, and punched cards.

D. Recent Modifications.

For the present study, several relatively minor modifications were made to the existing ORNL version of SPEC-4. No changes were made to the 
basic algorithms, rather only the output routines were revised. In terms of printed output, several edits which had been added at ORNL for diagnostic reasons were deleted. Also, the routine CILE2, which computed the final unfolded spectrum in a 51 energy-group structure frequently used at ORNL, was deleted since it gave unreliable results in the overlap region between detectors. I he tinal output table giving the unfoided spectrum and error estimates was reformatted for corivenience.

In terms of graphical output, the plotting routines which were added by R. M. Freestone were entirely replaced with updated routines. The new routines use the DISSPLA graphics software ${ }^{3}$ which provide greater flexibilities in plot construction. A second important feature of the DISSPLA software is that it allows for post-processing of the plot data, so that the SPEC-4 job becomes independent of plotting devices, and one of several DISSPOP routines ${ }^{4}$ are used to generate a plot on any graphics device.

It should be noted that several other modifications could have been made to SPEC-4, but insufficient time prohibited such improvements. Specifically, the input requirements could be greatly reduced by elimating data such as the methane parameters since the methane detectors are no longer used at the TSF. Also, all fixed dimensions could be converted to flexible dimensions, and run-time allocation of memory storage space could be installed. 


\section{INPUT REQUIREMENTS}

\section{A. Card Descriptions}

The input to the SPEC-4 program contains data used to specify the energy range values for protons in hydrogen, experimental and analytic correction factors which incorporate the physical characteristics of the hydrogen filled detectors, range-radius correction factors, and the measured pulse-height data from each experiment configuration. Original generalities in the input such as the methane energy-range data are still required, although they are not used for TSF applications.

Below is a list of the data input including card number, format, parameter name, and description.

Cards 1-31 (6F12.6)

$E(J), R H(J)$ Hydrogen range/energy data. [See Data Note \#1]

Cards 32-62 (6F12.6)

$E(J), R C(J)$ Methane range/energy data. [See Data Note \#1]

Card 63

(I2)

NSM Number of values in each of the next three arrays. [See Data Note \#2]

Cards 64-65 (10F7.0)

$\operatorname{CFE}(J) \quad$ Experimental correction factors. [See Data Note \#3]

Cards 66-67 (10F7.0)

CFS $(J) \quad$ Calculated correction factors. [See Data Note \#3]

Cards 68-69 (10F7.0)

$\operatorname{ROR}(\mathrm{J}) \quad$ Range/radius correction factors corresponding to the CFE's and CFS's. [See Data Note \#3]

(Note: The preceeding input always remains fixed for TSF measurements. The following data may change for each case.) 
Card 70

(I10)

NSPE

The number of points in the input neutron spectrum to follow. [See Data Note \#4]

Cards $71-77(6 \mathrm{E} 12.5)$

FU(J) Input spectrum values, in order of ascending energy in units of flux per unit lethargy. [See Data Note \#4]

Cards 78-84 (6E12.5)

$\mathrm{U}(\mathrm{J}) \quad$ The energy midpoints in MeV corresponding to the $\mathrm{FU}(\mathrm{J})$ 's, [See Data Note \#4]

Card $85 \quad$ (15A4)

TPLOT1 Flrst line of plot title. [See Data Note \#5]

Card 86

(15A4)

TPLOT2 Second line of plot title. [See Data Note \#5]

Card $87 \quad(7 F 10.0)$

CAL Analyzer energy calibration in MeV/Channel. [See Data Note \#6]

BBIAS Analyzer back bias in "channels." [See Data Note \#7]

EBOT Lowest energy to be analyzed. [See Data Note \#8]

EMAX Maximum energy to be analyzed. [See Data Note \#9]

$\mathrm{CH} \quad$ Number of channels for each pulse-height spectrum.

[See Data Note \#10]

SMT Numerical smoothing option 1.0 .. smoothing; 0.0 mo

smoothing. [See Data Note \#11]

RTST Flag indicating that more runs follow.

RTST $=1.0$ implies more to come

RTST $=0.0$ implles this is last run

Card $88 \quad(5 F 70.0)$

RAD Counter radius in centimeters; for TSF experiments this number is always 2.32 .

GPH Gas pressure of hydrogen in atmospheres at $15^{\circ} \mathrm{C}$. [See Data Note \#12]

GPC Gas pressure of Methane in atmospheres at $15^{\circ} \mathrm{C}$. [See Data Note \#12] 
RES Detector resolution in percent. Unfolded spectrum will be binned according to RES. [See Data Note \#13]

RCF Range correction factor. [See Data Note \#14]

Card 89

(I2)

ITIMES

SPEC-4 offers the option of successively processing several sets of data using the information from Cards 90 and 91 . ITIMES is the number of separate runs which is usually equal to 1 .

Card 90

(20A4)

TLE

A title card describing the experiment configuration being analyzed. It can be obtained from TSF fact sheet.

Card 91

FTIME

$(4 \mathrm{Fl} 2.5, \mathrm{I} 2,3 \mathrm{x}, \mathrm{I} 2)$

The foreground data normalization factor. [See Data Note \#15]

BTIME The background data normalization factor. [See Data Note \#15].

FGAIN No longer used.

BGAIN No longer used.

NOVFLO Number of overflow cards that involve wrap-around data. [See Data Note \#16]

INFLAG A signal to indicate the existence or nonexistence of a background run. NFLAG $=0$ indicate background data; NFLAG > 0, sets all background to zero.

Cards 92-117 (A4, A2, 6x, 10F6.0)

FCTS The foreground data. [See Data Note \#17]

Cards 118-143 (A4, A2, 6x, 10F6.0)

BCTS The background data. [See Data Note \#17]

- - - - - - - - - - - - - - - - - - - - - - - - - - - -

Cards 87-143 are entered three times with the data corresponding to each of the three counters SP-28 (10 atm), SP-26 (3 atm), and SP-25 (1 atm) in that order. 
Cards 258-260 (20A4)

TITL

Title printed and punched on final unfolded spectrum. This title should be comprehensive, including all three detectors. If the user does not use all three lines for the title, blank cards must be substituted for the unused cards.

Card 261

Blank card

This concludes the input deck.

B. Data Notes

1. At present, 92 values of range-energy $(R / E)$ data for protons in hydrogen $R H(J)$, and protons in methane $R C(J)$ are input. The energy $E(J)$ is input in units of MeV, and $R H(J)$ and $R C(J)$ are the ranges of protons in centimeters at $1 \mathrm{~atm}$ pressure and $15^{\circ} \mathrm{C}$. The values are input in order of increasing energy for both hydrogen and methane. These cards are always input.

2. The present vaiue for NSM is 12 which is generally recommended. The benefits derived from increasing this value are not great enough to warrant the amount of work it would take to do so.

3. The CFE $(J)^{\prime}$ 's, CFS $(J)$ 's, and $\operatorname{ROR}(J)^{\prime}$ 's are correction factors SPEC-4 utilizes to calculate the wall effects on the protonrecoil distribution. The code uses an analytic expression, essentially exact, to calculate the wall effects. However, it was found that the analytic results did not agree with experiments using monoenergetic neutrons, and that the disagreement was found to depend, in part, on the ratio of the proton range to the radius of the gas counter. Therefore, a set of correction factors (the CFE's, CFS's, and ROR's) were obtained through a series of curves, and are used to correct the analytic results. A more detailed analysis of the correction factors along with their tabulated values are found in Section 7 of the SPEC-4 manual ${ }^{2}$. These values are always input. 
4. R. M. Freestone settled on a value of 15 as a convenient number for NSPE. This number is dependent upon the energy group structure of the input spectrum, which should range from about $0.9 \mathrm{MeV}$ to $10 \mathrm{MeV}$. NEVER input values for this spectrum over $10 \mathrm{MeV}$, since this will cause the code to give bad results. With the group structure currently used for the NE-213 spectra, 37 points and the corresponding energy group midpoints are input to SPEC-4.

The energy midpoints are input in units of MeV, while the NE-213 spectrum (or equivalent) is input in units of flux per unit lethargy. This requires a supplementary calculation since the NE-213 spectrum is usually provided in units of flux per MeV. The conversion of the spectrum to flux per unit lethargy is performed utilizing the following equation

$$
\phi(U)=\frac{\phi(E)\left(E_{1}-E_{0}\right)}{\ln \left(E_{1} / E_{0}\right)}
$$

where $E_{1}$ and $E_{0}$ are the energy boundaries corresponding to the energy midpoints at which the $\phi(E)$ 's are tabulated. The high energy spectrum is input in order of ascending energy.

5. These two title cards will appear as the plot title produced at the end of the run. The titles should give adequate description of the plot and each line may be up to 60 characters long including the dollar (\$) sign which must appear as the final character in each 1 ine.

6. Each of the detectors, SP-28, SP-26, and SP-25 contains an alpha source deposited on its collector wire. The alphas deposit an equivalent proton energy which is dependent on the gas pressure. This energy depnsition, divided by the channel number of the centroid of the observed alpha peak, determines the value of CAL. However, the channel containing the centroid of the alpha peak must be corrected for the zero channel. Therefore, the zero intercept value given on the TSF "fact sheet" should be subtracted from the channel containing the alpha peak. Below is a table of the proton energy due to an alpha source for the 10, 3, and 1 atill detectors. 


\begin{tabular}{ccc} 
Detector & $\begin{array}{c}\text { Hydrogen } \\
\text { Gas Pressure }\end{array}$ & Proton Energy \\
\hline SP-28 & $10 \mathrm{~atm}$ & $4.57 \mathrm{MeV}$ \\
SP-26 & $3 \mathrm{~atm}$ & $1.35 \mathrm{MeV}$ \\
SP-25 & $1 \mathrm{~atm}$ & $0.407 \mathrm{MeV}$
\end{tabular}

7. BBIAS is the compliment of the multichannel analyzer zero error (intercept). It is the quantity to be added to the indicated channel to give the true channel. For example, if the analyzcr channel corrcsponding to zero energy is chlamel 2, then BBIAS $=-z$. Therefore, the negativc of the zero intercept repurled un the "fact sheet." should be input as BBIAS.

8. EBOT is the lowest energy (in MeV) to be analyzed. This parameter is one of the few parameters that can be legaliy juggled to accommodate the data. The value for EBOT can best be determined by visual examination of the raw data. A semilog plot of the raw data normally appears as a superposition of two lines: one line with a large neqative gradient at. low pulse-heights, and one line with a small negative gradient over the remaining pulse-heights. The low pulse-height contribution is from gamma-ray events, and EBOT should be chosen to exclude these channels. In the most recent work, an EBOT of $0.27 \mathrm{MeV}, 0.17 \mathrm{MeV}$, and $0.05 \mathrm{MeV}$ have been used for the SP-28, SP-26 and SP-25 detectors, respectively. However, these values should not be used without first visually examining the raw data.

9. EMAX is the parameter that determines the maximum energy to be unfolded. If left blank on the input card, EMAX is set internally to $1.4 \mathrm{MeV}$ for the $10 \mathrm{~atm} \mathrm{SP-28} \mathrm{detector.} \mathrm{For} \mathrm{the} \mathrm{subsequent.}$ counters (SP-26 and SP-25), the code uses EBOT and a fixed overlap of two resolution widths to determine EMAX values. If EMAX is entered explicitly, the input value will be used, which must be in units of MeV.

Care should be taken on how EBOT and EMAX are selected. First, they should not be too different from the counter ranges 
mentioned in Section I.C. of this report. Secondly, if the automatic feature is used, EBOT for the SP-28 detector determines EMAX for the SP-26 detector, and EBOT for the SP-26 detector determines EMAX for the SP-25 detector. Therefore, the user must carefully select the values for EBOT. In any case, the resulting ranges should be compared against the raw data to assure exclusion of the gamma-ray and alpha peak contributions. Also, the overlaps in the unfolded spectrum should be visually inspected.

10. At present, a 255-channel pulse-height analyzer is used to record the data. Therefore, $\mathrm{CH}=255$.

11. If SMT $=1.0$, smoothing of the raw data before processing is performed in the subroutine VSMTH using the "travelling average" method. Only if the raw data were especially good, and maximum resolution was desired, would no smoothing be considered. The penalty for smoothing is reduction in resolution, typically from $10 \%$ without smoothing to $15 \%$ with smoothing. Therefore, the value input for SMT will directly influence the value for RES (see Data Note 13). At present, there is an internal parameter, $\mathrm{NBCH}$, which specifies a lower channel cut-off for smoothing. This avoids the unnecessary smoothing of the unwanted gamma-ray contribution. The value of $\mathrm{NBCH}$ is currently 25 which should be adequate for most cases. If unusually high or low gamma-ray fields are encountered, it may be desirable to change the value of $\mathrm{NBCH}$.

12. GPH is the gas pressure for hydrogen, and depends on which detector is being considered. For the TSF experiments GPH is equal to 10 for SP-28,3 for SP-26, and 1 for SP-25. It is input in units of atmospheres. GPC is always zero since none of the detectors used in the TSF experiments contain methane.

13. RES is the desired unfolding resolution. The counters have an inherent resolution of about $8 \%$, but the data are seldom good enough statistically to take advantage of it. As stated in 
Data Note \#11, the value of SMT will determine the value for RES. If no smoothing is used, RES can be $10 \%$. However, if smoothing is used, RES should equal 15\% due to the penalty for smoothing. RES is input in units of percent.

14. The range correction factor (RCF) is used by SPEC-4 to help bring the code-calculated response function closer to reality. It is presently used only at higher values of ROR. When ROR exceeds 1.5, the ranges in the R-E tables for hydrogen and methane are multiplied by RCF, and these values are used to produce the modified response functions. RCF is detector dependent: the values are 1.10 for the $10 \mathrm{~atm} \mathrm{SP-28}$ detcctor, 1.03 for the $3 \mathrm{~atm} \mathrm{SP}-26$ detector, and 1.00 for the $1 \mathrm{~atm} \mathrm{SP-25}$ detector.

1b. Ihe foreground and background data normalization factors are the product of the measurement live-time and the reactor power. These numbers are reported on the "fact sheet." FTIME and BTIME should be input in units of s-kW. The normalization of the NF-213 spectrum (see nata №te 4) must also bc in these units.

16. The parameter NOVFLO is used to accommodate wrap-around data. The multichannel analyzer can only count up to 999,999 counts per channel, and, if the number of counts exceeds this value, it starts back at zero which causes erratic behavior of the data. However, wrap-around usually occurs only in the gamma-ray contamination, and therefore, it is of little importance. This data is usually not analyzed since it is cut. off by EBOT. However, if the user wishes to fix the wrap-around data, an integer input equal to the number of cards of foreground counts in $10 F 7.0$ format is placed here. There has not been any background wrap-around data to date and therefore there is no input to accommodate it.

17. The pulse-height data is input in the specified format if NOVFLO is equal to zero. If NOVFLO is not zero, NOVFLO number of cards are read in $A 4, A 2,4 x, 10 F 7.0$ format. At present, there are 26 cards of raw data for each run (with 255 channels). 
III. JCL REQUIREMENTS

Below is a list of the job control language (JCL) needed to run SPEC-4 utilizing a variety of post processors for graphical output.

// JOB CARD

$/ /{ }^{*}$ CLASS CPU91 $=25 S, I \emptyset=1.2$, REGI $\emptyset N=270 K$, CARDS $=50$

$1 *$ DPTIØNS PAGE $=62$

$/ /$ EXEC SPDASCR

//SYSIN DD*

T. xxxyyyyy.anyname

//SPEC EXEC PGM=SPEC4, REGION=270K,

// PARM=' $S I=50, S \emptyset=51, S P=52, I D=-1, I U=-1, E D=-1, E U=-1, F D=-1$ '

$/ / G D . S T E P L I B \quad D D D S N=X . D T I 46103 . P R \emptyset G, D I S P=S H R$

$/ /$ GD. FT06F001 DD SYSOUT $=A$

$/ / G \emptyset$. CDMPØUT DD DISP $=(N E W, C A T L G)$,

// UNIT $=\operatorname{SPDA}, \operatorname{SPACE}=(4000,(300,30), \mathrm{RLSE})$,

// DSN=T.xxxyyyyy . anyname

//GØ. FT07F001 DD SYSQUT $=B$

//GD.FT05F001 DD *

(Data)

(Post-processor)

$/ 1$

The data set names in the temporary data sets ( $T$.xxxyyyyy.anyname) are described in the programmers guide. The letters $x x x$ correspond to the user ID and yyyyy correspond to the users charge number.

The user has several options in choosing a post-processor to produce the plot output from the SPEC-4 program. There are a few limitations, however, on the use of one of these post-processors. The three postprocessors given below will likely satisfy most plotting needs.

The JCL for the Gould plotter is given below. The user cannot obtain a punched deck of the unfolded spectrum when using the Gould plotter since the plot data is transmitted as punched output. In the standard SCL for 
the job, insert a "/*ROUTE PUNCH REMOTE7" after the "/DPTIØNS" card. Al so, the "//GD.FT07F001 DD SYSDUT=B" card must be changed to "//GD.FT07 F001 DD DUMMY." The post-processor JCL is as follows:

//GPLT EXEC GLDPLT, REGION=110K

$/ /$ CØMPIN DD DSN=T. xxxyyyyy . anyname, DISP=SHR

//FT05F001 DD *

DRAW $=1-E N D$

$/ *$

The COMPIN data set must correspond to the CØMPØUT data set defined previously.

Running jobs using the Gould plotter will allow quick examination of the plot. When the user is satisfied with the results, he can submit a job to be plotted on the 763 or 925 Calcomp plotters. Using either of these two units, the user can also obtain a punched deck of the unfolded spectrum for further use. Therefore, the "/*RøUTE PUNCH REMØTE7" card should be removed, and the "//GD.FT07F001 DD DUMMY" card should be changed back to "//GØ.FTO7F001 DD SYSøUT=B." Below is the JCL for the 925 Calcomp plotter.

/ /DSKPLT EXEC PGM=PØPD92, REGIØN=110K, CØND=EVEN

//STEPLIB DD DSN=SYS2. DISSPQP, DISP=SHR

//FT06F001 DD SYSøUT=A

//CØMPIN DD DSN=T. xxxyyyyy. anyname, DISP=SHR

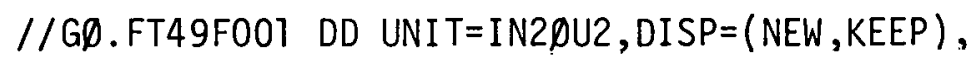

// DCB $=S Y S 2$. DISKDCB,

$/ / \operatorname{SPACE}=(3208,(90), \mathrm{RLSE}), \mathrm{DSN}=\mathrm{PL} \emptyset \mathrm{T} \emptyset \mathrm{UT}$

$/ / P L \emptyset T S U B S$ DD DSN=SYS2. JGSPL $\emptyset T H, D I S P=(S H R, P A S S)$

//FT05FO01 DÓ *

DRAW $=1-E N D$

/*

The 925 Calcomp plotter uses a ball-point pen with a default color of black. 
Below is the JCL for the 763 Calcomp plotter.

// EXEC PGM=PØPD76, REGIØN=110K

$/ / S T E P L I B \quad D D D S N=S Y S 2$. DISSP DP, DISP=SHR

//FT06F001 DD SYSØUT=A

//COMPIN DD DSN=T. xxxyyyyy. anyname, DISP=SHR

$/ /$ GØ. FT49F001 DD UNI T=IN2ØU2, DISP=(NEW, KEEP),

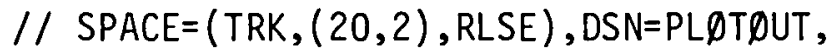

// DCB=SYS2. DISKDCB

$/ /$ PL $\emptyset$ TSUBS DD DSN=SYS2. JGSPL $\emptyset T H, D I S P=S H R$

//FT05F001 DD *

DRAW $=1-E N D$

I*

The 763 Calcomp plotter uses a black felt-tip pen giving a high quality plot suitable for reproduction. 
THIS PAGE

\section{WAS INTENTIONALLY LEFT BLANK}




\section{OUTPUT FROM SPEC-4}

The output of the TSF version of SPEC-4 has been considerably expanded from the RSIC version. Much of what is printed has been added as a means of monitoring the performance of the code and the data manipulation technique.

The code first prints the Range-Energy tables for protons in hydrogen and protons in methane. Errors in inputting the gas pressure will show here. The high energy input spectrum is printed next. This is the input spectrum (NE213 for SP-28 run) along with the energy midpoints. The input spectrum is followed by a table of Response Correction Factors. These factors are calculated in the code using the input correction factors and other input parameters dependent on the particular detector. If the last entry in the right column is much greater than 2.5, then there is probably trouble with the value of EBOT. Adjusting EMAX and EBOT has a direct effect on the values for the Response Correction Factors.

The next table of output is the differential of the response matrix, followed by a number of diagnostic parameters which require a detailed study of the code to utilize. This output is generated by subroutine SNIDOW.

The output of subroutine SPEC2S is printed next, followed by the tables of the raw input foreground and background counts. A second set of smoothed foreground and background counts is printed which represents the results of the subroutine VSMTH. The "net" pulse-height spectrum, i.e., the difference of the smoothed foreground and background counts is printed next, followed by a table of the high energy pulse heights distribution. This latter table is the high energy input spectrum converted into pulse heights. A normalized difference spectrum is printed next which is equal to the smoothed net spectrum minus the high energy contributions. An edit of some input parameters is printed next followed by a binned spectrum which is presented as the calculated spectrum. This is 
the final result for the particular detector being analyzed, and is the input spectrum for the next detector (at lower pressure).

The above sequence of prints is performed for each of the three detectors used in unfolding a hydrogen spectrum. After the three sets of prints, a summary edit is produced labeled "Output Spectrum Ordered by Detector." This table is headed by the final three title cards, and presents the final results for each detector starting with the $1 \mathrm{~atm}$ detector and proceeding to the $10 \mathrm{~atm}$ detector. The punched card deck which is produced from the run will contain the same information as this table, but in two formats. One format is column-oriented and corresponds exactly to the printed output, while the other format is row-oriented for convenient input into auxilary programs.

The final table printed is titled "Output Spectrum Ordered by Energy." This table presents the same information as the previous table except that it is ordered strictly by increasing energy. This format has its advantages, but does obscure the overlap regions.

The final edit pertains to the plot output. If any problems were encountered in the plotting routines, an error message will be printed in this section. Also, a summary of the plot parameters such as axis lengths and step sizes are given. 


\section{OPERATING EXPERIENCE AND RECOMMENDATIONS}

Several recommendations based on accumulated operating experience were included in the input data notes (Section II.B) and output descriptions (Section IV). This section is intended to expand on those comments.

The first thing a user should do is plot the raw data. Since the raw data is supplied to the analyst in the form of punched cards, it is relatively easy to feed the cards to a simple computer code for automatic plotting. A sample program to perform such a task is listed in Appendix $B$ along with a sample plot. This plot can serve to locate EBOT, and also to identify any anomolies in the data such as bad data points or mis-punches. The user should look for the data to be a fairly straight line between the low-channel gamma-ray contamination and the high-channel alpha peak. Any significant bumps or dips that occur in this straight line region will cause poor results.

The second thing a user should do is tabularize his input data for a particular case. This step involves setting up a table of input parameters, and a table of the high energy input spectrum and corresponding energy midpoints. An example of this type of procedure is included in Appendix C. Performing this step gives the user quick reference to the input for a particular configuration and also an easy way to check his input. Finally, the user keypunches the data and runs the calculation.

As stated earlier, the only parameters the user can vary are the selections for EBOT and EMAX. Almost all other parameters are determined from data on the "fact sheet." In the input data notes (Section II.B) some past values for EBOT were discussed. These values are intended as guidelines, the actual values should be determined from visual examination of the raw channel data. Al though EBOT is input in units of MeV, it can be related to channel numbers by dividing by the value of CAL. EMAX is presently set at 1.5 for SP-28, and left blank for SP-26, and SP-25. This allows the code to use the automatic overlap routine for the SP-26 and SP-25 detectors. 
The energy limits on the plot produced by SPEC-4 are currently set at $0.04 \mathrm{MeV}$ and $2.0 \mathrm{MeV}$. Therefore, if the user extends the analysis range outside of these limits, the code should be changed to accommodate the new limits. This requires a trivial change to subroutine SCALE.

A sample SPEC-4 case is given in Appendix $C$ including a listing of the card input, portions of the printed output, and the resulting spectrum plot. Finally, Appendix $D$ gives a listing of a source program which can be used to read the punched output from SPEC-4 to produce a printed edit of the unfolded spectrum identical to the final table produced by SPEC-4, and also produce a SPEC-4 type plot. 


\section{ACKNOWLEDGEMENTS}

The authors wish to thank R. M. Freestone for his original work on SPEC-4 at ORNL, and for his informal user's guide which appears as App. A. Also, we would like to thank C. C. Webster and F. J. Muckenthaler for their insight and recommendations on operating the SPEC-4 code. 


\section{REFERENCES}

1. P. W. Benjamin, C. D. Kemshall, and A. Brickstock, "Analysis of Recoil Proton Spectra," United Kingdom Atomic Energy Authority, AWRE 09/68.

2. "SPEC-4 Calculated Recoil Proton Energy Distributions From Monoenergetic and Continuous Spectrum Neutrons," Radiation Shielding Information Center, PSR-99.

3. DISSPLA - Display Integrated Software System Plotting Language, Integrated Software Systems Corporation, San Diego, California, Vols. I and II $(1970)$.

4. DISSPOP - DISSPLA Post-Processor Option, Integrated Softwares Systems Corporation, San Diego, California (1976). 
Appendix A

A Brief Guide to the SPEC-4 Unfolding Code

R. M. Freestone, Jr. 
THIS PAGE

\section{WAS INTENTIONALLY \\ LEFT BLANK}


The purpose of this note is to provide a simple "cookbook" for running the TSF version of the SPEC4 code, used to unfold neutron spectra over the energy range from approximately $8 \mathrm{keV}$ to $1 \mathrm{MeV}$. The organization following some general remarks, will follow the deck stacking exactly.

The data which SPEC4 is designed to unfold are pulse height distributions obtained with spherical, gas-filled, proton recoil proportional counters, called Benjamin counters, having a radius of $2.32 \mathrm{~cm}$. At the present time (November 1976) two counters are used, although as many as four were used in earlier measurements. One counter, identified as SP28, is filled with pure hydrogen gas at a pressure of $10 \mathrm{~atm}$, and is used in the higher energy end of the spectrum. The other counter, SP24, is filled to a total pressure of $3 \mathrm{~atm}$ with a mixture consisting of $85 \% \mathrm{H}_{2}$, $10 \% \mathrm{CH}_{4}$ (methane), and $5 \%$ nitrogen.

A normal set of data from the TSF will consist of one run with SP28 in so-called one-parameter mode, one run with SP24 in one-parameter mode, and two runs with SP24 in two-parameter mode, for a total of four. In one-parameter mode the data are acquired simply as counts vs pulse height, with a conventional pulse height analyzer. To describe the two-parameter acquisition, a mention of the events within the counter is necessary. Both recoil protons resulting from neutron-hydrogen collisions and electrons, usually from gamma-ray interactions in the counter walls, are created. Since the maximum energy that an electron can deposit is defined by its flight along a diameter of the counter, gamma rays can be discriminated against in one-parameter analysis by simply discarding from the analysis all data below the maximum possible electron pulse. This treatment obviously sets a lower energy limit on one-parameter analysis since low energy protons will be undistinguishable from electrons of proportionate energy.

It has been noted, however, that pulses due to electrons have a slower rate of rise than equally energetic pulses due to proton recoils. In two-parameter analysis both the magnitude of the pulse $V$ and its rate-of-rise, $d V / d t$, are measured and stored using the TSF ND4420 
minicomputer-based system as a $32 \times 128$ array of $d V / d t$ vs. V. (Actually, $d V / d t / V$ is stored, but the effect is the same.) A typical $d V / d t / V$ "slice" will have a strong peak due to electrons at the left, with a slow tail which extends under a peak due to protons at the right. Before the twoparameter data can be analyzed by SPEC4 it must be preprocessed to remove the electron contribution. This is done external to SPEC4 by a short code called GSTRIP.

We now proceed to a detailed description of the input to SPEC4. TSF data is presently output on paper tapes which are submitted by TSF personnel to a DEC-10 program called "TSF" which produces a deck or decks of punched data cards. The cards are routinely delivered to Bldg 6025 . More or less simultaneously (accent less!) F. J. Muckenthaler delivers to the data analyst a "fact sheet" giving all of the information required to unfold the data. In the discussion below, card numbers will be used as section headings. We begin immediately after the "//GO.FT05F001 DD *" card

Cards 1-31 (6E12.6)

Ninety-two values of range-energy values for protons in hydrogen. These cards are always input.

Cards 32-62 (6El2.6)

Ninety-two values of range-energy values for protons in methane. Always input.

Card 63 (12)

NSM: The number of values in the three arrays to follow (12 at present, and I see no reason to change).

Cardș 64-65 (10F7.0)

CFE: Experimental correction factors. The code uses an analytic expression, essentially exact, to calculate wall effect corrections. It was found that for unknown reasons the analytic results did not agree with experiments using monoenergetic neutrons. The CFE's and the CFS's that follow correct the analytic result to agree with experiment. 
CFS: Calculated correction factors. See above.

Cards 68-69 (10F7.0)

ROR: Range/radius correction factors. Part of corrections noted above. To this point input has been standard and unvarying. We now begin the input which varies from job-to-job.

Card 70 (110)

NSPE: The number of points on the input spectrum to follow. I have settled on 15 as convenient.

Cards $71-73$ (6E12.5)

FU: SPEC4 computes the contribution to the pulse height spectrum from neutrons having energies greater than the upper limit of analys is and subtracts it out. It therefore requires an estimate of the higher energy spectrum. Ideally, this should be an NE213 spectrum measured under the same conditions as the proton recoil spectrum. In practice this is not always available, so a "nearly alike" spectrum or a calculated spectrum must be used. A SPEC4 result is not usually very sensitive to this input. FU must be in units of flux/lethargy units. I use:

$$
\phi(u)=\frac{\phi(E) \Delta E}{1 u\left(E_{1} / E_{0}\right)}
$$

Cards 74-76 (6E12.5)

$U$ : The midpoints in MeV of $E_{1}, E_{0}$, above.

$$
\left(E_{0}+\Delta E=E_{1}\right)
$$

Card 77 (10A8)

TPLOT: A title for the log plot produced as part of the output. (DISKPLOT). (10A8)

Card 78 (7F10.0)

CAL, BBIAS, EBOT, DUMY, CH, SMT, RTST. CAL is the detector calibration in MeV/channel. SP28 contains an alpha source deposited on its collector wire. The alphas deposit an equivalent proton 
energy of $4.57 \mathrm{MeV}$. This number, divided by the channel number of the centroid of the observed alpha peak, gives.CAL.

SP24 contains $5 \% N_{2}$. The ${ }^{14} \mathrm{~N}(n, p){ }^{14} \mathrm{C}$ reaction with thermal neutron deposits $611 \mathrm{keV}$ of energy in this peak. Obviously, 0.611/channel number will give CAL in MeV/channel. This is the method used for one-parameter data. For two-parameter data the previously mentioned fact sheet gives the energy in keV corresponding to channel 128. In current practice this is usually $2220 \mathrm{keV}$ for the low gain segment, w5 keV for the high gain run. BBIAS is the complement of the multichannel analyzer zern error. It is the quantity to be added to the indicated data channel to give the true channel. For example, if the analyzer channel corresponding to zero energy turns out to be channel 2, BBIAS $=-2$.

EBOT is the lowest energy to be analyzed in the run being treated. This is sometimes a delicate choice. Although theoretically the counters have a definite gamma-electron energy upper limit, intense gamma fields tend to smear the gamma peak to higher pulse heights. A suitable EBOT can usually be chosen by plotting the raw data and noting the point at which the high and steep gamma peak joins the relatively slowly diminishing proton curve. However, any unfolded result showing a peak at its low energy end should be carefully examined for possible gamma contamination. In my most recent work I have used an EBOT of $2270 \mathrm{keV}$ for SP28.

DuMY is presently an unuscd constant. In the uriyinal version of the code it was EMAX, the maximum energy to be unfolded. In the present version EMAX is set to $1.4 \mathrm{MeV}$ for the SP28, 10 atm data by the code, and automatically for later runs. $\mathrm{CH}$ is the number of channels ur dula - 255 for spico data.

SMT is the smoothing option. SPEC4 offers via subroutine VSMTH the option of smoothing the raw data before processing. Traveling average smoothing is used. I have found smoothing to be nearly

For SP26 use $1.35 \mathrm{MeV} /$ channel number; for SP25 use $0.407 \mathrm{MeV} /$ channel number. (From RMF notes of 4/9/74 - Runs 1389C, 1389B, 1390D, and 1390C) 
always desirable. Only in a situation where the raw data were super-good and maximum resolution was desired would I consider not smoothing. SMT $\leqslant 0$., do not smooth. RTST is the flag indicating that more runs follow. RTST $=1$., more to come; RTST $=0$., this is last run (of a set of four).

Card 79 (7F10.0)

$R A D, G P H, G P C, R E S, R C F$. RAD is the counter radius- $-2.32 \mathrm{~cm}$. GPH is the hydrogen gas pressure in atm:. $10 \mathrm{~atm}$ for SP28. GPC is the methane gas pressure, 0 . for SP28.

RES is the desired unfolding resolution. The counters have an inherent resolution of about $8 \%$, but the data are seldom good enough statistically to take advantage of it. I have used $10 \%$, but $15 \%$ gives the most believable results. RCF is a range correction factor used by SPEC4 to help to bring the code-calculated response functions closer to reality. For SP28 it is 1.10; as will be seen later, it varies according to the particular detector.

Card $80(12)$

ITIMES: SPEC4 offers the option of successively processing several sets of data'using the information from Cards 80 and 81 . ITIMES is the number of runs, but since the TSF never replicates runs, ITIMES is always 1.

Card 81 (10A8)

TLE: A title card describing the particular data set being analyzed. obtained from F.J.M's fact sheet.

Card 82

FTIME, BTIME, FGAIN, BGAIN, NFLAG. (4F12,5,5x,I2).

FTIME is the foreground normalization factor, the product of live time and reactor power. Units are min*W.

BTIME is the background normalization factor, as above.

FGAIN, BGAIN: Historical remnants; not used.

NFLAG: A signal to indicate the existence or nonexistence of a background run. If NFLAG is nonzero, background is set to zero in column 55 . 
Cards 83 to $108(12 x, 10 F 6.0)$

255 channels of data

If a background run was made, the cards comprising its 255 channels follow immediately--no blanks or signals. At one time I included. an option for correcting for gain differences between foreground and background but found that with usually only fractional channel differences between the two, and using smoothing, this option was more trouble than it was worth.

This completes the processing of one run. The pronram $($ RTST = 1.) will go back to the format of card 80 and should, or will, read in the data for a one-parameter run with SP24. The same cautions with regard to EBOT exist. RCF is 1.07 for SP24. There will be 255 channels of data for this run.

The code is so written that an automatic overlap of two resolution widths is made in going from one run to the next. This overlap region should be examined with care in the output. Often troubles with gamma contamination may be discovered in this region. A second problem, particularly with data having poor statistics, is that sometimes the tall of the $\mathrm{N}_{2}$ calibration peak may contaminate the high-energy end of the SP24 one-parameter distribution. In such cases the only remedy is to go back to the raw data and by observation juggle the EBOT's to get into "clean" areas.

After processing the SP24 one-parameter data the code will again return to the format of card 80 to find the parameters for the next run. Since this run is the output of GSTRIP operating on the $32 \times 128$ array, the number of channels, $\mathrm{CH}$, will be 128 .

A final return to the format of card 80 , this time with RTST $=0$., completes the processing of a four-run Benjamin counter spectrum.

The last three cards in the input deck should be a title for the tabular output of results. If three cards are not needed, pad with blanks. 
The output of the TSF version of SPEC4 has been considerably expanded from that available with the original version available from RSIC. Much of what is printed has been added as a means of monitoring the performance of both the code and the data acquisition techniques.

The code first prints the range-energy table. Errors in inputting the gas pressures will show here.

The high-energy input spectrum is printed, followed by the response correction factors. If the last entry in the right column is much greater than 2.5, there is probably trouble with EBOT's.

Next is printed the differential of the response matrix, followed by a number of values which really require a detailed study of the code to utilize. They probably could be scratched.

The output of the subroutine SPEC2S, the high energy contribution to be subtracted, is printed. It is again printed in a normalized, more easily used form below as "High Energy Pulse Heights to be Subtracted."

The raw foreground and background counts, followed by the smoothed net counts, are printed.

The normalized difference spectrum is printed. This is the input spectrum minus the high energy contribution.

Finally, a binned grouped spectrum is printed, followed by the real result, the unfolded spectrum "Calculated Neutron Spectrum."

The above are printed for each of the four runs. At the finish a neat, ordered table of results is printed followed by some binning information and finally by the spectrum in the commonly used 51-group structure.

A log Calcomp plot is also produced. 
$A-10$

The final output is a punched card replica of the result table to be used to produce reproduction quality output when needed (my program "EDIT"). 
B-1

Appendix B

Listing of the RAWDAT Program 


\section{THIS PAGE}

\section{WAS INTENTIONALLY \\ LEFT BLANK}


A source listing of a sample graphics program for plotting "raw" pulse-height data is shown in Fig. 1. This program uses DISSPLA graphics software and the associated post processors. Although the purpose of most of the input parameters is obvious from the parameter name, IPTS requires additional explanation. IPTS specifies the number of data points which are to be read in a F7.0 format rather than the usual F6.0 format. Normally, IPTS $=10$ * NOVFLO where NOVFLO is the overflow parameter input to SPEC-4.

Usual1y, RAWDAT will produce 6 plots: a foreground and a background plot for each of the 3 counters. Sample plots are shown in Figs. 2 and 3 which display the foreground and background data for a $3 \mathrm{~atm}$ detector. Visual examination of the plots shows the relatively straight line between the low-channel gamma-ray contamination and the high-channel alpha peak. Hence appropriate values of EBOT and EMAX can be obtained from the plots. 
DIMENSTON X (255), Y (255), XLABEL (4), YLABEL (5), TITLE $1(15)$, TITLE2(15)

DATA NPTS, IMARKR, I NAME, IHT 1, IHT2, NMARK, HITE/255,8,100,-3,2,-1,.18/

DITA XIAGP,L/4 GCHAN, 4 HNEL, 4 HNIIMB, 4HERD,

DATA YLABPI/4HCOUN, 4 HTS P, 4 HER C, 4 HHANH, 4 RELS

CALL COMPR.S

5 READ $(5,100, E N D=99)$ IPLT, IPTS, NLINE, NDATA, PAGEX, PAGFY

READ $(5,200)$ X PIYOR, YPHYOR, XAXIS, YAXIS , XOR IGN, XSTEP, YORIGN, YMX

READ $(5,300)$ TITLEI,TITLE,

100 PORA AT $(4(2 \mathrm{X}, \mathrm{I} 4), 2(2 \mathrm{X}, \mathrm{P} 6,0))$

200 PORMAT $(6(2 X, P 6.0), 2(2 X, F 8.0))$

300 POR.MAT (15A 4$)$

D. $10 \quad t=1$, NPTS

$10 \times(I)=I$

IF (NDATA.R.Q. 1) GO TO 40

IF (IPTS. F. . O) GO Ta a 3

PQEAD $(5,400)$ (Y (I) , I=1, IPTS)

400 FORMAT $(10 \mathrm{x}, 10 \mathrm{~F} 7.0)$

A.3 IPTS $1=I$ DTS +1

R.AO (5,500) (Y (I), I = I QTS 1, NPTS)

500 TORMAT $(12 \mathrm{X}, 10 \mathrm{PG} .0)$

Do $70 \mathrm{~J}=1$, UPTS

$\operatorname{IF}(Y(J) \cdot E \cap .0 .0) Y(J)=1.0$

70 CONTINUP.

WRI?P. $(6,50)$

50 PORYAT (5X, THE RAW DATA FROM THP HCA TO BE PLUTTED')

HPITE $(6,30) Y$

30 FORMAT $(10(2 X, P R .0))$

40 CALL $B$ GNPL (IPLT)

CILL PAGE (PAGEX, PAGEY)

CATL PHYSOR (XPHYOR, YPHYCR)

CALL MARKER (IMARKR)

CALL GRACE (0.0)

CALL HEIGHT (HITR)

CALL TITLF ( $1 H, 1$, XLA BDL, INAME, YLABDL, INAYE, XAXIS, YAXIS)

CALL HFADIN (TITLE1, INAME, THT 1, NLINE)

CALL URADIN (TITLE2, INAME, IHT 2, NLINF)

IF (YORIGN+YUY.E?.0.0)GO TO 91

PATN $=$ YARTSA

YMAX $=$ Y YX

Giv $\operatorname{li} 092$

P1 $Y$ YIY $=Y(1)$

$Y M A X=Y(1)$

Dก $20 . j=2$, NPTS

IF (Y (J). LT. IMIN) THIn=Y (J)

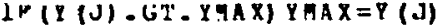

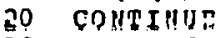

92 RRTTE $(6,60)$ YHIN, YHAX

60 PORMAT $(2 X, 1 Y M I N=0 P 8,0,5 X, 1 Y M A X=0 P Q, 0)$

CALL ALGPLT (YAIN, YMAX, YAXIS, YORIG, YCYCL)

CALL YLOS (XORIGN, XSTEP, YORIG, YCYCL)

CALL DTIRBA (XAXIS, YAXIS)

GALL GURVE (X, Y, HRTS, NAATK)

GALL ENDPL (IPI.T)

Gก TO 5

99 CALL DON BP L

S'LUY

END

SIIAROITT NF, RTTPRM (XA, YA)

TS I Z $\mathrm{B}=0.10$

GALI VAAM

CALL BLNK1 $(0,0$, XA-TSIZE, 0.0,YA,0)

CALL GRID $(0,1)$

CALL RESET ("BLNK 1 ')

CALL. 3LNK2 $(0.0, X A, 0.0, Y A-T S I Z E, D)$

CALL GRTD $(1,0)$

CALL RESET ('BLNK 2 ')

RETUTN

END

Fig. 1. Source Listing of the RAWDAT Program for Plotting Pulse-Height Data from the Hydrogen Counters. 
ORNL-DWG-80-12241

SPECTRUM MODIFIER SHIELD CONF IGURATION

RUN NO. 1460A; 3 ATM DETECTOR (SP26); FOREGROUND DATA

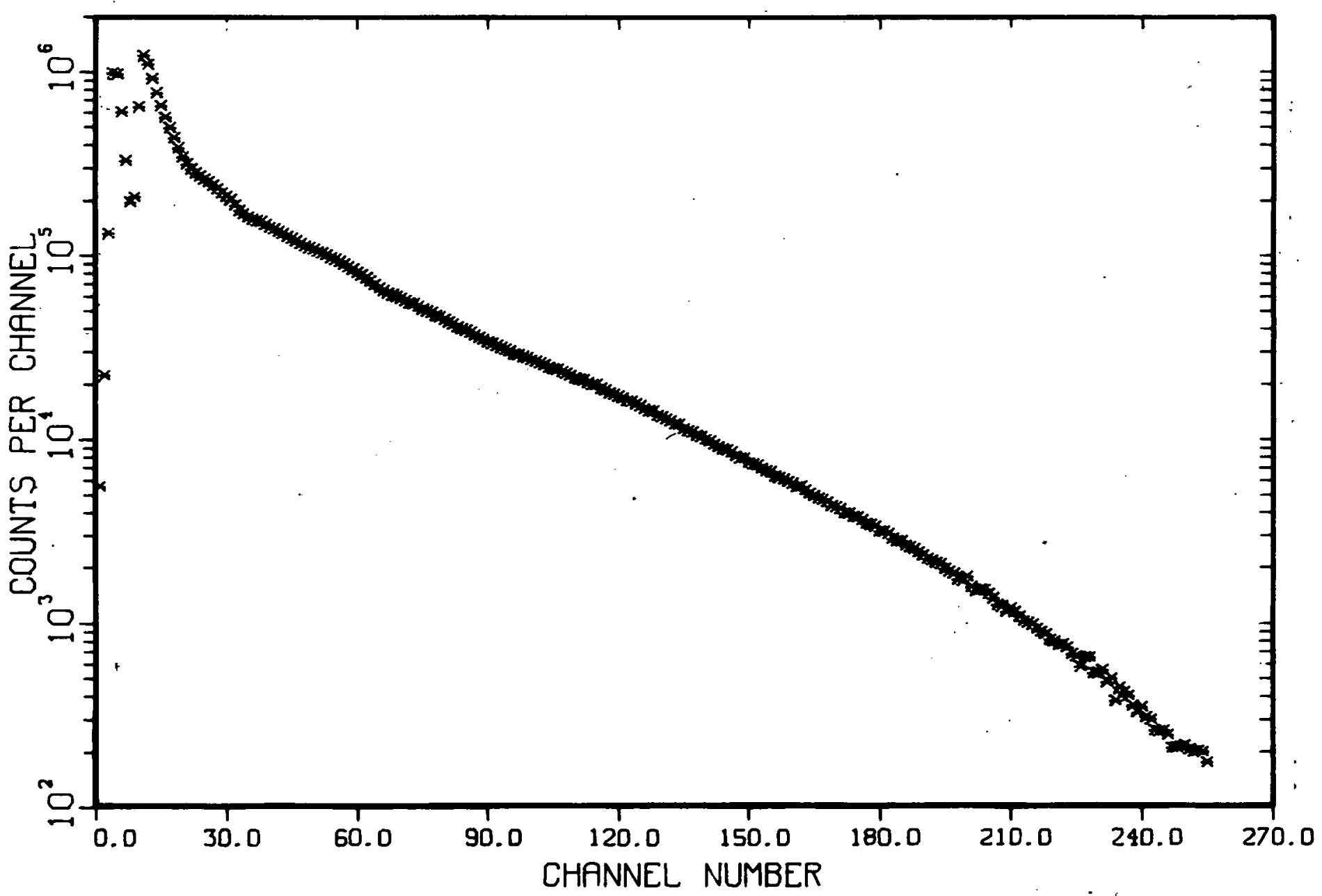

Fig. 2. Sample RAliCAT Plot. 


\section{ORNL-DWG-30-12242 \\ IPECTRUM MODIF IER SHIELD CONF IGURAT ION}

RIJN NC. 1460B: 3 ATY DETECTOR (SP26); BACKGROUND DATA

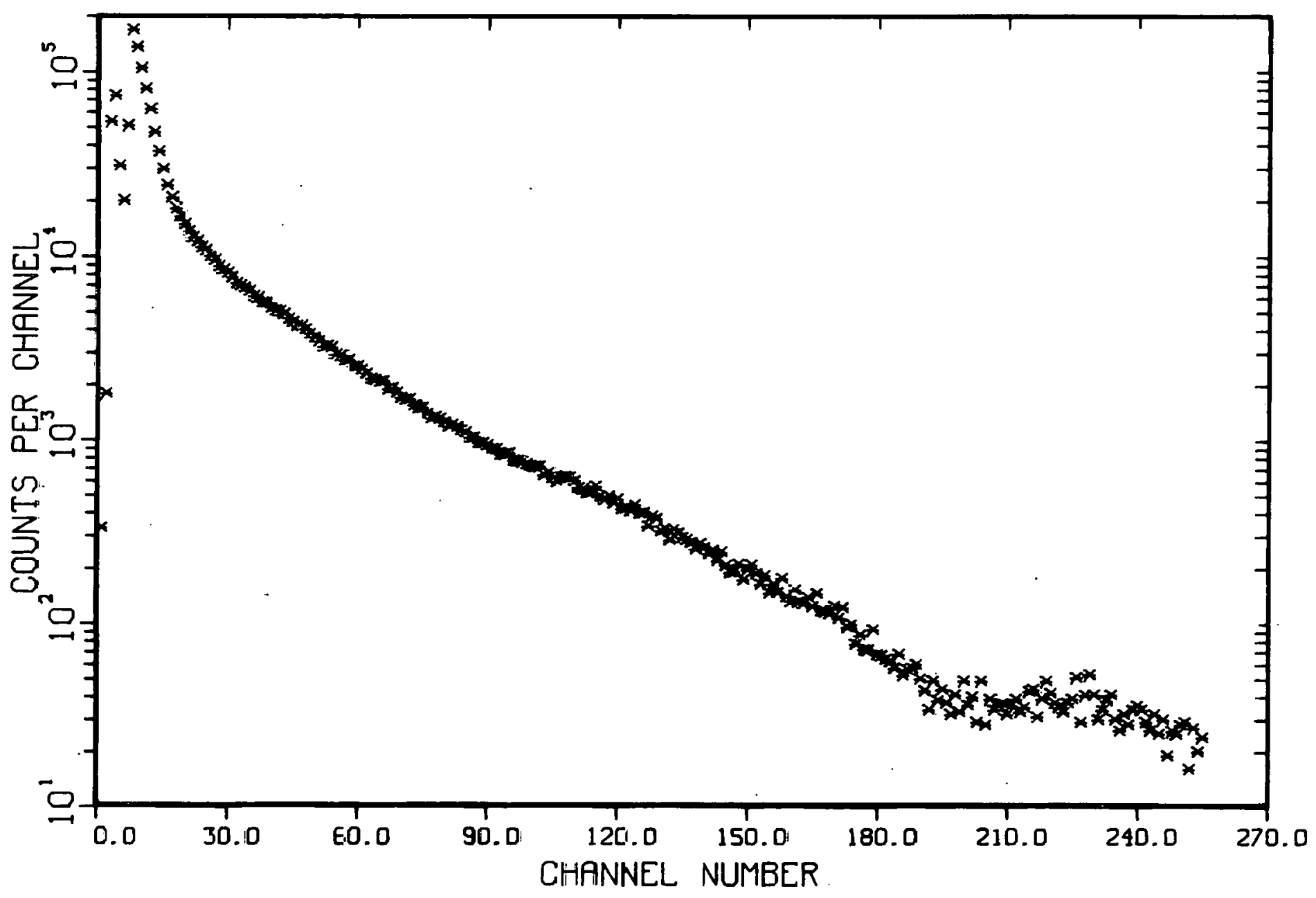

罗

Fig. 3. Sample RAWDAT Plot. 
Appendix C

A Sample Problem for SPEC-4 
THIS PAGE

\section{WAS INTENTIONALLY LEFT BLANK}


As described in Sections I and II, SPEC-4 requires as input an estimate of the neutron flux above the highest measurable energy of the gas detectors. For most TSF applications, this spectrum is provided by an NE-213 measurement made under the same conditions as the hydrogen counter measurements. The unfolded NE-213 spectrum is normally expressed in units of $\mathrm{n} /\left(\mathrm{cm}^{2} \cdot \mathrm{s} \cdot \mathrm{kW} \cdot \mathrm{MeV}\right)$, i.e., flux per unit energy. In order to convert the energy flux to a lethargy flux as required by SPEC-4, a simple calculation is required. Table 1 shows the results of a flux conversion for a sample NE-213 spectrum.

When performing a SPEC-4 calculation, it is generally good practice to tabularize the required input parameters for easy reference. Table 2 shows a sample table including the usual source which provides the input values.

A listing of the input for a typical SPEC-4 calculation is given in Fig. 4. The corresponding output from SPEC-4 is listed in Fig. 5. Only the output from the $10 \mathrm{~atm}$ detector is given, for brevity, and also the final edit of the full spectrum from the three detectors. Figure 6 shows the plot which is produced by SPEC-4 including the estimated errors. If poor overlap between the detectors is observed, EBOT may have been improperly chosen, or the data may be in error. Small discrepancies in the overlap can always be expected. 
Table 1. Conversion of NE-213 Spectrum from Energy to Lethargy NE-213 Case: 7773B,C Spectrum Modifier only

\begin{tabular}{|c|c|c|c|c|c|}
\hline \multicolumn{2}{|c|}{$E_{L B}(M e V)^{a}$} & $E_{M i d}(M e V)$ & $\frac{E_{U B}-E_{L B}}{\ln \left(E_{U B} / E_{L B}\right)}$ & $\phi(E)^{b}$ & $\phi(U)$ \\
\hline $\begin{array}{l}1 \\
2 \\
3 \\
4 \\
5 \\
6 \\
7 \\
8 \\
9 \\
10 \\
11 \\
12 \\
13 \\
14 \\
15 \\
16 \\
17 \\
18 \\
19 \\
20 \\
21 \\
22 \\
23 \\
24 \\
25 \\
26 \\
27 \\
28 \\
29 \\
30 \\
31 \\
32 \\
33 \\
34 \\
35 \\
36 \\
37 \\
38\end{array}$ & $\begin{array}{l}0.859 \\
0.957 \\
1.057 \\
1.157 \\
1.257 \\
1.361 \\
1.461 \\
1.560 \\
1.660 \\
1.760 \\
1.872 \\
2.016 \\
2.198 \\
2.397 \\
2.601 \\
2.801 \\
2.998 \\
3.197 \\
3.399 \\
3.604 \\
3.807 \\
4.029 \\
4.303 \\
4.603 \\
4.897 \\
5.194 \\
5.496 \\
5.792 \\
6.096 \\
6.405 \\
6.697 \\
7.037 \\
7.486 \\
7.986 \\
8.497 \\
9.010 \\
9.501 \\
10.000\end{array}$ & $\begin{array}{l}0.907 \\
1.007 \\
1.107 \\
1.205 \\
1.310 \\
1.412 \\
1.511 \\
1.010 \\
1.710 \\
1.813 \\
1.932 \\
2.100 \\
2.296 \\
2.497 \\
2.703 \\
2.898 \\
3.098 \\
3.297 \\
3.501 \\
3.707 \\
3.906 \\
4.153 \\
4.454 \\
4.752 \\
5.042 \\
5.346 \\
5.645 \\
5.938 \\
6.254 \\
6.556 \\
6.839 \\
7.236 \\
7.767 \\
8.237 \\
8.758 \\
9.261 \\
9.741\end{array}$ & $\begin{array}{l}0.907 \\
1.006 \\
1.106 \\
1.206 \\
1.308 \\
1.411 \\
1.510 \\
1.610 \\
1.710 \\
1.816 \\
1.943 \\
2.106 \\
2.296 \\
2.498 \\
2.700 \\
2.898 \\
3.096 \\
3.297 \\
3.500 \\
3.705 \\
3.917 \\
4.165 \\
4.451 \\
4.749 \\
5.044 \\
5.343 \\
5.642 \\
5.942 \\
6.249 \\
6.550 \\
6.866 \\
7.259 \\
7.7 .33 \\
8.239 \\
8.751 \\
9.253 \\
9.748\end{array}$ & $\begin{array}{l}4.511+1 c \\
4.452+1 \\
3.897+1 \\
3.413+1 \\
2.988+1 \\
2.662+1 \\
2.440+1 \\
2.278+1 \\
2.117+1 \\
1.942+1 \\
1.751+1 \\
1.567+1 \\
1.251+1 \\
1.028+1 \\
8.527 \\
7.403 \\
6.481 \\
5.639 \\
1.907 \\
1.333 \\
3.984 \\
3.536 \\
3.445 \\
3.070 \\
2.685 \\
2.329 \\
2.027 \\
1.713 \\
1.398 \\
1.176 \\
1.032 \\
8.714-1 \\
6.940-1 \\
5.552-1 \\
4.194-1 \\
3.236-1 \\
2.526-1\end{array}$ & $\begin{array}{l}4.092+1 \\
4.478+1 \\
4.308+1 \\
4.116+1 \\
3.910+1 \\
3.755+1 \\
3.684+1 \\
3.660+1 \\
3.620+1 \\
3.528+1 \\
3.402+1 \\
3.174+1 \\
2.872+1 \\
2.568+1 \\
2.302+1 \\
2.146+1 \\
2.007+1 \\
1.859+1 \\
1.718+1 \\
1.605+1 \\
1.560+1 \\
1.473+1 \\
1.534+1 \\
1.458+1 \\
1.354+1 \\
1.244+1 \\
1.144+1 \\
1.018+1 \\
8.736 \\
7.703 \\
7.087 \\
6.326 \\
5.367 \\
4.574 \\
3.670 \\
2.994 \\
2.462\end{array}$ \\
\hline
\end{tabular}

$a_{\text {Lower boundary of energy bin. }}$

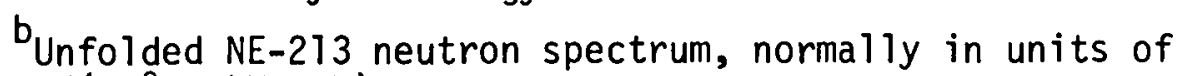
$\mathrm{n} /\left(\mathrm{cm}^{2} \cdot \mathrm{s} \cdot \mathrm{kW} \cdot \mathrm{MeV}\right)$.

Read as $4.511 \times 10^{1}$. 
Table 2. Fact Sheet for Hydrogen Counter

Configuration: Spec Mod only

Detector: SP-28; $10 \mathrm{~atm}$

\begin{tabular}{cclcc}
\hline Card \# & Columns & Parameter & Value & Source $^{\mathrm{a}}$ \\
\hline 1 & $1-2$ & NSM & 12 & 1 \\
2 & $1-10$ & NSPE & 37 & 1 \\
3 & $1-10$ & CAL & 0.0090513 & 2 \\
& $11-20$ & BBIAS & -1.8 & 2 \\
& $21-30$ & EBOT & 0.270 & 3 \\
& $31-40$ & DUMMY & 0.0 & 1 \\
& $41-50$ & CH & 255.0 & 1 \\
& $51-60$ & SMT & 1.0 & 3 \\
4 & $61-70$ & RTST & 1.0 & 3 \\
4 & $1-10$ & RAD & 2.32 & 1 \\
& $11-20$ & GPH & 10.0 & 3 \\
& $21-30$ & GPC & 0.0 & 3 \\
& $31-40$ & RES & 0.15 & 3 \\
5 & $41-50$ & RCF & 1.10 & 1 \\
6 & $1-2$ & ITIMES & 1 & 2 \\
& $1-12$ & FTIME & $503.0(\mathrm{~kW} \cdot \mathrm{s})$ & 2 \\
& $13-24$ & BTIME & $195.2(\mathrm{~kW} \cdot \mathrm{s})$ & 1 \\
& $25-36$ & FGAIN & $X$ & 1 \\
& $37-48$ & BGAIN & $X$ & 3 \\
\hline
\end{tabular}

a Source of input value: $1=$ normally fixed

$$
\begin{aligned}
2= & \text { supplied by TSF experimenter } \\
3= & \text { determined by detector and/ } \\
& \text { or condition of data. }
\end{aligned}
$$




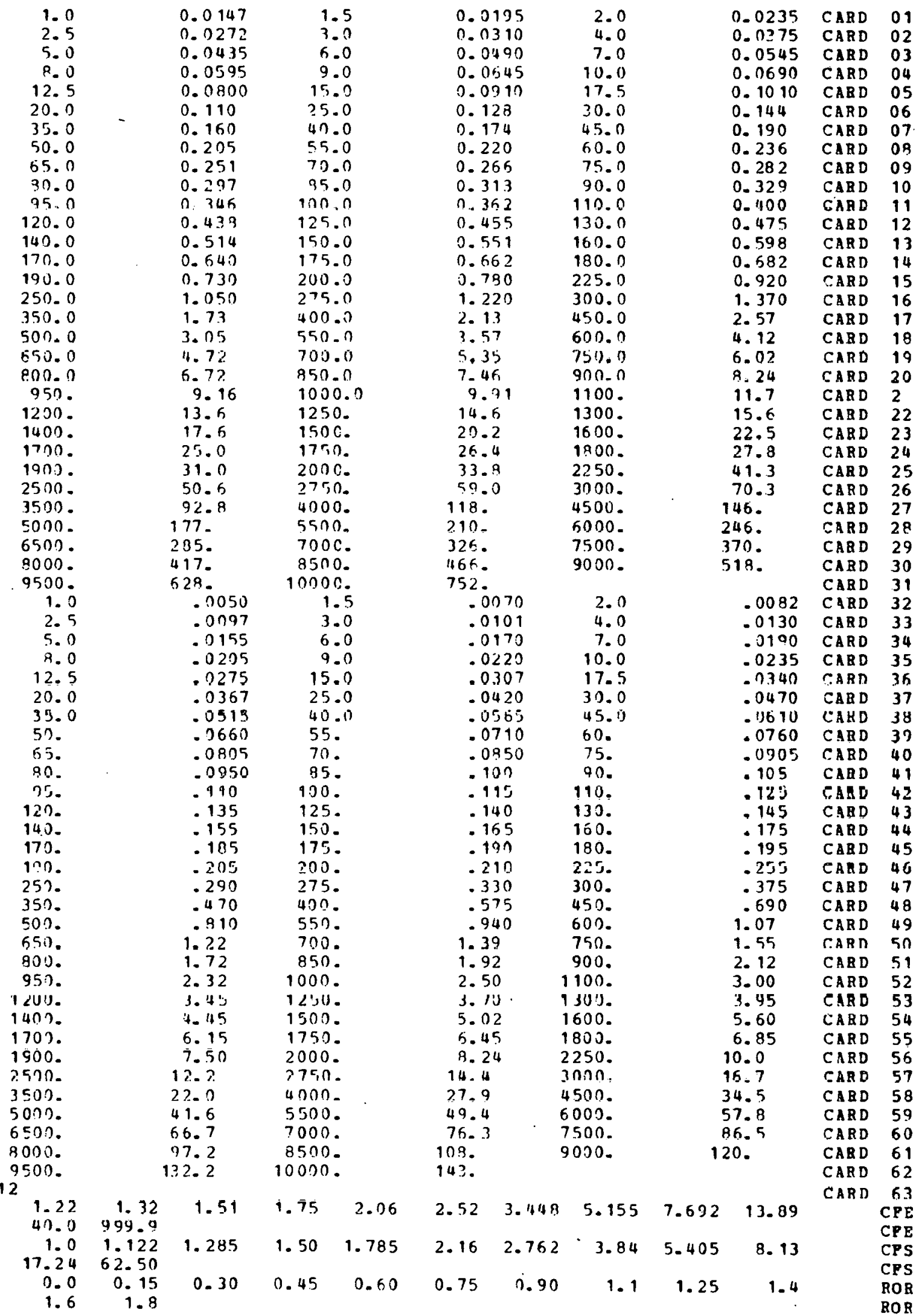

Fig. 4. Input Listing for SPEC-4 Sample Problem. 
37 POINTS PROM NE.213 RTN 7773 B AND 7773 C ON $2 / 28 / 79$ FOR JOJACAO 1

$\begin{array}{cccccr}40.7182 & 44.7959 & 4.3 .0781 & 41.1573 & 39.1011 & 37.5541 \\ 36.9478 & 36.6579 & 36.1980 & 35.2312 & 34.0220 & 31.7437 \\ 28.7165 & 25.6790 & 23.0186 & 21.4550 & 20.0680 & 18.5910 \\ 17.1750 & 16.0500 & 15.5050 & 14.7250 & 15.3370 & 14.5790 \\ 13.5430 & 12.4420 & 11.4380 & 10.1770 & 8.7359 & 7.7032 \\ 7.0869 & 6.3256 & 5.3670 & 4.5744 & 3.6699 & 2.9944 \\ 2.4624 & & & & & \\ .90594 & 1.0055 & 1.1059 & 1.2047 & 1.3095 & 1.4121 \\ 1.5107 & 1.6100 & 1.7095 & 1.8125 & 1.9323 & 2.1000 \\ 2.2961 & 2.4988 & 2.7026 & 2.3994 & 3.0975 & 3.2965 \\ 3.5009 & 3.7074 & 2.9061 & 4.1528 & 4.4540 & 4.7521 \\ 5.0422 & 5.3459 & 5.6453 & 5.9390 & 6.2542 & 6.5557 \\ 6.9390 & 7.2352 & 7.7365 & 8.2364 & 8.7578 & 9.2613\end{array}$

SPECTROA MODIFIER SHIELD CONPIGURATION\$

RUNS $1459 \mathrm{~A}, 1459 \mathrm{~A}, 1460 \mathrm{~A}, 1460 \mathrm{~B}, 1461 \mathrm{NB}, 1461 \mathrm{Nh} / \mathrm{JOJHCAO} 1.8$

$$
\begin{array}{ccccccc}
.009051297 & -1.8 & 0.34 & 1.5 & 255.0 & 1.0 & 1.0 \\
2.32 & 10.0 & 0.0 & 15.0 & 1.10 & \\
1 & & 0.0 & & &
\end{array}
$$

1459 A $\quad 1769 \quad 4744 \quad 12767 \quad 47523 \quad 445808 \quad 854610713035558905 \quad 5176451021071$ $13489071141025949893793766 \quad 669342568488 \quad 485341421146380305 \quad 351262$ $1459 \mathrm{~A}$ $1459 \mathrm{~A}$. 031193032171214159366152083145527139151132303125578119431113057 041107130102234097069092429088965084930081942078412076093073688 051071901069549067063064899063159060790058593056479055071052677 061051175049467048014045917044538042856041861039940038726036917 071035689034075033308032256031124030035029133028395027215026365 $081025466024 R 81024015023060022404021960021404020792020222019605$ $091019268019081018 ? 1701760901744$ ค0 16303016245015703015272014821 101014391014037013431013331012947012576012173011734011251010873 111010618010403010038009679009471009209008990008744008362008140 121007349007718007552007299006964007089006693006457006328006098 131005099005687005631005455005243005113005013004796004720004651 1410045010043060041550041100040220038380036710034.32003525003321 $1510033290 \cap 3251003113002989002905002914002638002599002494002415$ 161002428002382002253012151002038002032001958001845001820001747 171001763001582001616031448001434001397001359001374001284001239 181001226001139001104001120001079000911000973000911000950000842 191000792000784000732000669000679000627000599000583000547000513 201000517000451000439000473000428000392000358000375000345000325 211000319000305000253000281000241000230000194000179000195000179 $2210001830001470001410) 0132000111000120000102000091000077000069$ 231000074000049000060000053000053000040000045000029000041000036 241000035000023000027000031000036000033000029000029000021000032 000020000032000020000026000018010000

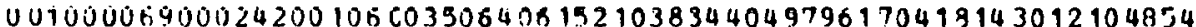
011079100061367047642037835031050025591020350019485017856016237 021014731013525012261011380010687009717009127008370007772007233 031006617006237005858005454005144004314004364004162003914003617 $041003512003194003113002917 C 02796002697002599002427002484002301$ $0510022600022090020780019960020040019300018110017180016460015 R 7$ 06100147700145.3001525001320001265091241001217001170001171001057 071001097001109001021000036000962000885000861000860000787000812 091000748000696300693000660000629000613000591000591000538000565 091000512000518000463000431000437000394000383000378000349000326 101000229000323000307000295000252000254000298000224000243000261 111000225000235000260000212000200000210000185000174000204000202 12100018000019.3000174000189000165000159000137000158000150000138 131000122000110000117020125000115000105000134000121000092000111 141200100000096000097002073000063000067000073000089000074000058 151000067000066000066000053000058000051000052000053000055000054 $161000049000039000045000 n 37000051000043000042000038000045000035$ 171000033003024000034000031000027000030000035000019000022000025 
$1453 \mathrm{~A}$

145 A A

$1458 A$

14589

$1458 \mathrm{~A}$

$1458 \mathrm{a}$

$1458 \mathrm{~A}$

$1458 \mathrm{~A}$

.00452716

2. 32

RUN

$1460 \mathrm{~A}$

$1460 \mathrm{~A}$

14604

14601

$1460 \mathrm{~A}$

$1460 \mathrm{~A}$

$1460 \mathrm{~A}$

14601

$1460 \mathrm{~A}$

$1460 \mathrm{~A}$

$1460 \mathrm{~A}$

$1460 \mathrm{~A}$

$1460 \mathrm{~A}$

$1460 \mathrm{~A}$

$1460 \mathrm{~A}$

$1460 \mathrm{~A}$

$1460 \mathrm{~A}$

1460 A

$1460 \mathrm{~A}$

$1460 \mathrm{~A}$

1460 :

$1460 \mathrm{~A}$

$1460 \mathrm{~A}$

$1460 \mathrm{~A}$

$1460 \mathrm{~A}$

$1460 \mathrm{~A}$

$91460 \mathrm{~B}$

914609

814605

ค $1460 \mathrm{~B}$

91460 ?

$81460 \mathrm{~B}$

$91460 n$

$31460 \mathrm{~B}$

$31460 \%$

$91460 \mathrm{P}$

314609

314603

$91460 \mathrm{~B}$

$3146.3 \mathrm{~B}$

₹ $1460 \mathrm{~B}$

$91469 \mathrm{~B}$

914603

$91460 \mathrm{~B}$

81460R

8 $1460 \mathrm{~B}$

A $1460 \mathrm{~B}$

$91460 \mathrm{~B}$

3 $1460 \mathrm{~B}$
191000025000023000026000016000022000014000021000016000018000012 191000015000016000011000014000013000010000011000014000014000008 201000016000009000009020019070011000009000009000010000009000010 211000006000007000008000009000099000003000006000004000003000003 221000004000005000004000002000008000006000004000004000006000004 231000003000005000505000005000001000004000004000005000004000006 241000003000002000005070005000004000001000003000003000005000000 000006000005000003000007000004002000$$
-1.8
$$
0.17
0.0
255.0
1.0
1.0
1. 03

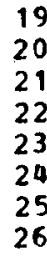

1460A BKGD 14603 SP-26(? AIM) ZERO ZR=1.8; ALPHA CALIB=300.0 1398.0

493.6

0

$\begin{array}{lllllll}554722296131936 & 984737971103602571326483 \quad 195540 & 208576 \quad 643819\end{array}$ 12305251093960912520755271651930563169494530434130394266343113 021313506294771279984270447261124251692241589231389220247209784 $03119991918313917696 \subseteq 169669162509158177155346153113147779143372$ 041139998134919131308126401123557119149116259112790109545107184 051104649102788100252097241094933692691088993086652083647080771 061078429075138072195069185066534064391062243060986059351058056 071056236055234054219052944050774049660049038047212046526044883 081043450042405040804039615038975037994036855035771034861023739 091033215032319031478030815030058029095028773028124027774027011 101026559026014025464024548024145023925023204022873022264021607 111021203020986020274019859019820019898018510017888017537017219 121016769016305016204015582015195014734014365014235013583013360 1.31012774012726012211012069011516011159010979010504010393010085 141009840009479009161008941008782008559008173007947007994007518 151007409007271006937006724006710006284006165006113005929005814 161005491005539005305005081004924004762004718004551004311004266 171004162003951003936003779003737003622003461003402003339003147 181003140003045002860002784002783002627002577002517002429002326 191002217002181002112002082001061001897001847001716001600001776 2010015650014870015130015100014.370013550012500012 .33001146001201 211001140001085001026001009000979000933000901000870000915000795 221000750000760000734000679000659000576000646000649000531000533 231000554000477000499000376000443000421000402000357000325000351 $2410003100 \mathrm{CU} 299000261000256000260000246000209000209000213000217$ 000205000199000202000198000174010000 001000330001781053379073512030824019958050784167786135647104424 01109043906191504 EBB $00367450 ? 9574024065020755018097016405014 R 80$ 021013612012621012057011165010776010032009567008853008482008148 031007669007125006951015768006494006078005931005627005608005266 041005089005052004875004593004399004187004203004014003797003642 051003449003242003297003205002940002995002716002734002526002535 061002422002305002158002125002074002090001888001916001812001698 071001660001665001548001488001502001394001311001341001314001251 ดรุ 091000994000895000836000933000849000775000770000763000742000725 101000719000721000647000666000622000593000631000639000629000602 $11100055000053800051 \Xi 000520000559000494000473000494000452000476$ 121000421000426000409000443000390000400000338000385000371000319 131000325000284000327000310000294000289000276000254000271000259 141000240009250000220000245000208000130000192000211000174000197 151000209000187900164000184000147000164000149000177000141000133 161000153000132000129000139000124000147000118000116000113000125 171000107000122000095000099000077000096000072000072000093000068 191000067000064000002000057000068000052000056000057000060000050 191000043000034000049000038000044000037000032000041000033000049 201000036000040000029900049000029000739000034000036000037000032 211000036000039000033000035000043000044000031000039000049000042 22100003700003500003300.0037000039009051000029000041000053000041 


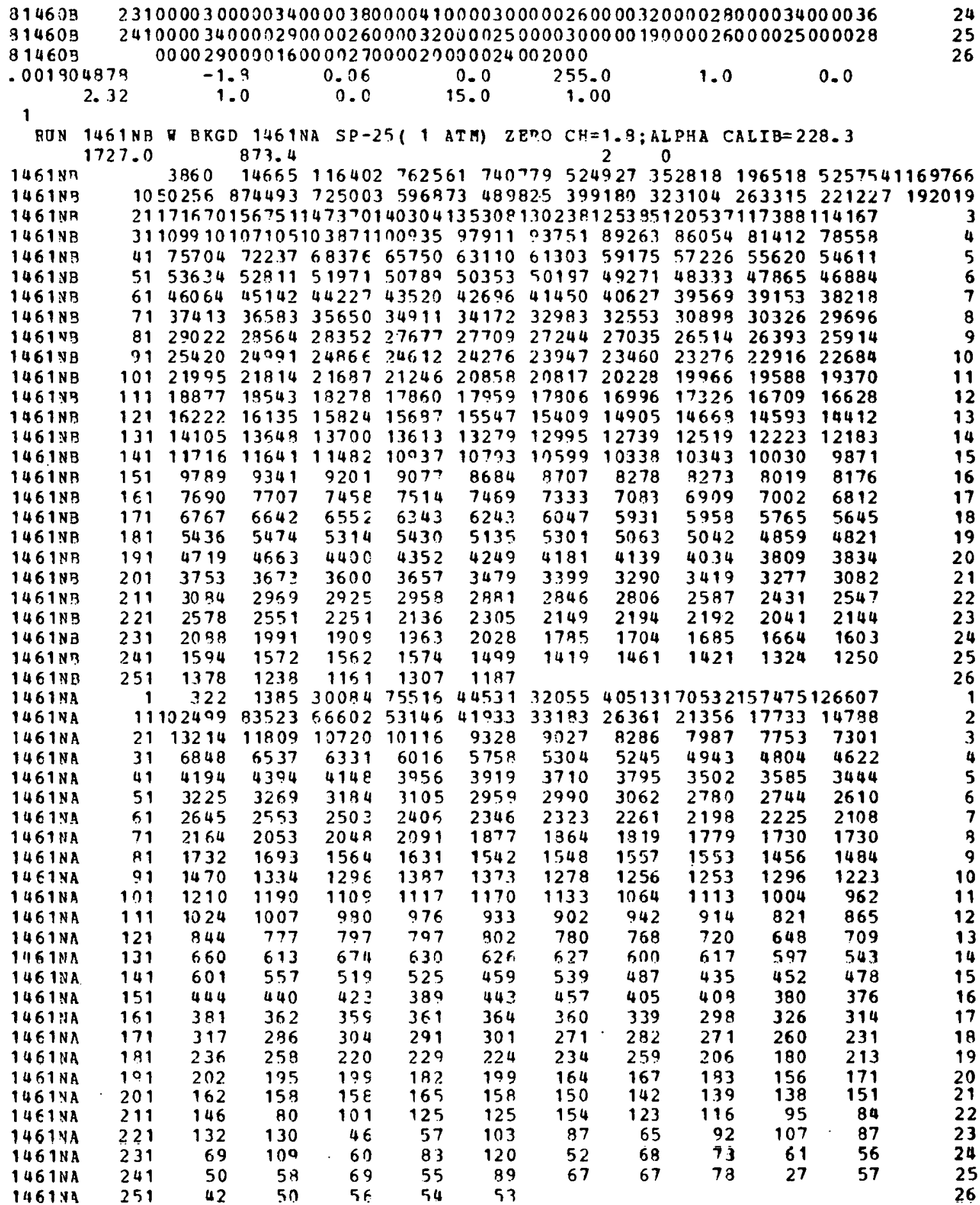

RUNS 1459 A (RK GD 1458A), SP-28(10 ATH): 1460A (BKGD 1460B),SP-26(3 ATA):

$1461 N 3$ (RKGD 1461NA),SP-25(1 ATM) A-CALIB (1461C-1461D(1 ATA)): DET 460CH

ON CL BEHIND SPEC MOD NE213 INPUT SPECTRUY=7773B,C ON $2 / 28 / 79$ : HCAO1

Fig. 4. Cont'd 
RANGE ENERGY DATA

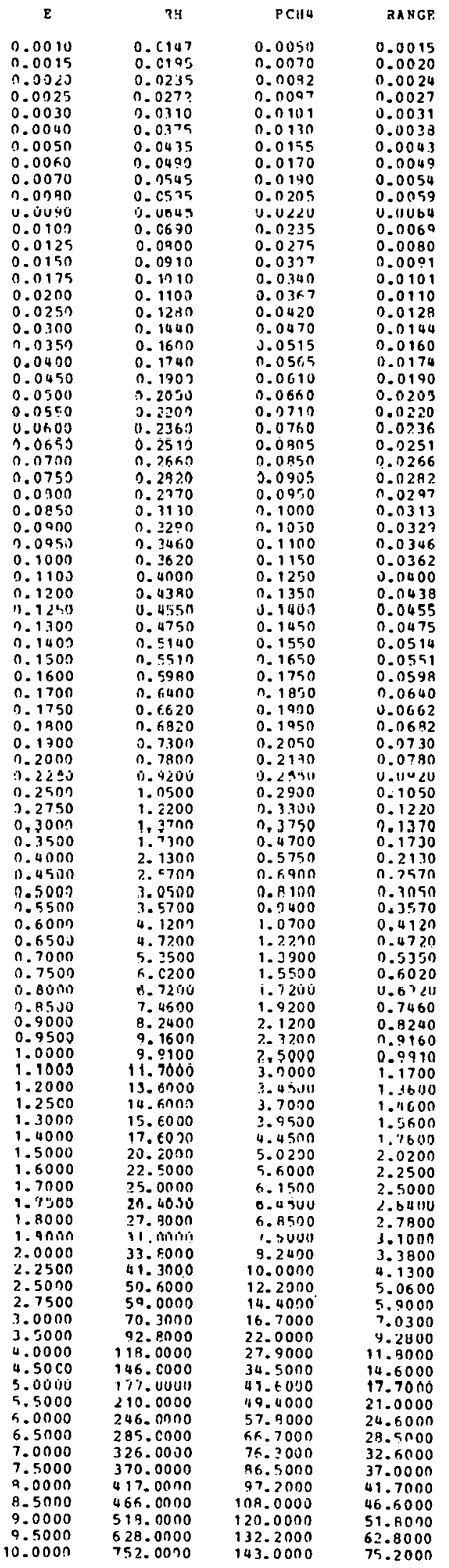

Fig. 5. Listing of Output from SPEC-4 Sample Problem. 
INPUT SPECTRUA

\begin{tabular}{|c|c|c|c|c|c|c|c|c|c|c|c|c|c|c|c|c|c|}
\hline 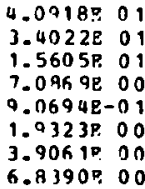 & $\begin{array}{l}4.4785 \mathrm{E} \\
3.1744 \mathrm{E} \\
1.4725 \mathrm{E} \\
6.3256 \mathrm{E} \\
1.0066 \mathrm{E} \\
2.1000 \mathrm{E} \\
4.152 \mathrm{E} \\
7.2352 \mathrm{E}\end{array}$ & $\begin{array}{ll}0 & 1 \\
0 & 1 \\
0 & 1 \\
0 & 0 \\
0 & 0 \\
0 & 0 \\
0 & 0 \\
0 & 0\end{array}$ & $\begin{array}{l}4.307 \mathrm{EE} \\
2.3716 \mathrm{P} \\
1.5327 \mathrm{P} \\
5.3670 \% \\
1.10698 \\
2.2961 \mathrm{E} \\
4.4540 \mathrm{P} \\
7.73650\end{array}$ & $\begin{array}{ll}0 & 1 \\
0 & 1 \\
0 & 1 \\
0 & 0 \\
0 & 0 \\
0 & 0 \\
0 & 0 \\
0 & 0\end{array}$ & $\begin{array}{l}4.11578 \\
2.56798 \\
1.45795 \\
4.5744 \mathrm{E} \\
1.20478 \\
2.49888 \\
4.75218 \\
8.73648\end{array}$ & $\begin{array}{ll}0 & 1 \\
0 & 1 \\
0 & 1 \\
0 & 0 \\
00 \\
00 \\
00 \\
0 & 0\end{array}$ & $\begin{array}{l}3.9101 \mathrm{P} \\
2.3019 \mathrm{E} \\
1.3543 \mathrm{E} \\
3.6699 \mathrm{E} \\
1.3096 \mathrm{P} \\
2.7026 \mathrm{E} \\
5.0422 \mathrm{E} \\
8.757 \mathrm{Q}\end{array}$ & $\begin{array}{ll}0 & 1 \\
0 & 1 \\
01 & 1 \\
00 \\
0 & 0 \\
00 \\
00 \\
00\end{array}$ & $\begin{array}{l}3.7554 \mathrm{E} \\
2.1455 \mathrm{E} \\
1.2442 \mathrm{E} \\
2.3944 \mathrm{D} \\
1.4121 \mathrm{E} \\
2.8984 \mathrm{E} \\
5.3459 \mathrm{~B} \\
9.2613 \mathrm{E}\end{array}$ & $\begin{array}{l}01 \\
11 \\
01 \\
00 \\
00 \\
00 \\
00 \\
00\end{array}$ & $\begin{array}{l}3.6848 \mathrm{E} \\
2.006 \mathrm{~B} \\
1.1438 \mathrm{E} \\
2.4624 \mathrm{E} \\
1.5107 \mathrm{E} \\
3.0975 \mathrm{E} \\
5.6453 \mathrm{E} \\
9.7411 \mathrm{E}\end{array}$ & $\begin{array}{ll}0 & 1 \\
00 & 0 \\
00 \\
00 \\
00 \\
00\end{array}$ & $\begin{array}{l}3.6559 \mathrm{E} \\
1.8591 \mathrm{E} \\
1.0177 \mathrm{E} \\
1.6100 \mathrm{~g} \\
3.2965 \mathrm{E} \\
5.9380 \mathrm{P}\end{array}$ & $\begin{array}{l}10 \\
00 \\
00\end{array}$ & $\begin{array}{r}3.6193 \mathrm{E} \\
1.7175 \mathrm{E} \\
8.7 .15 \mathrm{BE} \\
1.7095 \mathrm{E} \\
3.5009 \mathrm{E} \\
6.2542 \mathrm{P}\end{array}$ & $\begin{array}{ll}0 & 1 \\
0 & 1 \\
0 & 0 \\
& 0 \\
0 & 0 \\
0 & 0 \\
0 & 0\end{array}$ & $\begin{array}{l}3.52819 \\
1.60508 \\
7.70328 \\
1.91258 \\
3.70748 \\
6.55578\end{array}$ \\
\hline
\end{tabular}

RESPONSE COBRETTON PACTORS

$\begin{array}{ccc}\text { EHID } & \text { SUIDOH } & \text { EXPT } \\ & & \\ 0.3236 & 1.0540 & 1.2642 \\ 0.3779 & 1.0685 & 1.2761 \\ 0.4414 & 1.0874 & 1.2917 \\ 0.5230 & 1.1153 & 1.3145 \\ 0.6181 & 1.1622 & 1.3668 \\ 0.7224 & 1.2236 & 1.4385 \\ 0.8492 & 1.2152 & 1.5437 \\ 1.0033 & 1.4709 & 1.7175 \\ 1.1801 & 1.7279 & 1.9977 \\ 1.3840 & 2.1470 & 2.5041\end{array}$

MATRIX OP IONOANERGETI? NPOTPON DIPPBRENTIAL RECOIL PROTON DISTRIBUTIONS

\begin{tabular}{|c|c|c|c|c|c|c|c|c|c|c|}
\hline $\begin{array}{l}5.0880 \mathrm{E}-01 \\
3.040 \mathrm{PE}-02 \\
2.1235 \mathrm{E}-02 \\
1.5291 \mathrm{P}-02 \\
1.1026 \mathrm{P}-02 \\
9.5169 \mathrm{E}-03 \\
6.5226 \mathrm{E}-03 \\
5.1489 \mathrm{E}-03 \\
4.1229 \mathrm{E}-03\end{array}$ & $\begin{array}{l}0.0 \\
3-99098-01 \\
2.18548-02 \\
1.51158-02 \\
1.11418-02 \\
9.55678-03 \\
6.63898-03 \\
5.2100 P-03 \\
\text { 3. } 11678-03\end{array}$ & $\begin{array}{l}0.0 \\
0.0 \\
3.1273 \mathrm{E}-01 \\
2.0589 \mathrm{E}-02 \\
1.4706 \mathrm{E}-02 \\
1.1437 \mathrm{E}-02 \\
8.8460 \mathrm{E}-03 \\
6.8961 \mathrm{P}-03\end{array}$ & $\begin{array}{l}0.0 \\
0.0 \\
0.0 \\
2.3+115-01 \\
1.8 .3455-02 \\
1.39698-02 \\
1.09555-02 \\
7.99448-03 \\
7.9778-03\end{array}$ & $\begin{array}{l}0.0 \\
0.0 \\
0.0 \\
0.0 \\
1.7982 \mathrm{E}-01 \\
1.5298 \mathrm{E}-02 \\
1.2017 \mathrm{E}-02 \\
9.6701 \mathrm{E}-03 \\
7.6437 \mathrm{~B}-07\end{array}$ & $\begin{array}{l}0.0 \\
0.0 \\
0.0 \\
0.0 \\
0.0 \\
1.3497 \mathrm{E}-01 \\
1.2747 \mathrm{E}-02 \\
1.0635 \mathrm{E}-02\end{array}$ & $\begin{array}{l}0.0 \\
0.0 \\
0.0 \\
0.0 \\
0.0 \\
0.0 \\
9.9931 E-02 \\
1.3373 P-02\end{array}$ & $\begin{array}{l}0.0 \\
0.0 \\
0.0 \\
0.0 \\
0.0 \\
0.0 \\
0.0 \\
7.0965 \\
1.161\end{array}$ & -02 & $\begin{array}{l}0.0 \\
0.0 \\
0.0 \\
0.0 \\
0.0 \\
0.0 \\
0.0 \\
0.0\end{array}$ & 1.0 \\
\hline
\end{tabular}

S.12

$1.52200-034.9316 \mathrm{~g}-03 \quad 4.5181 \mathrm{E}-03 \quad 5.4777 \mathrm{E}-03 \quad 7.1292 \mathrm{E}-03 \quad 7.0418 \mathrm{E}-039.4649 \mathrm{~g}-039.8405 \mathrm{E}-031.0863 \mathrm{E}-02 \quad 3.1893 \mathrm{E}-02$

RANGE/RADIOS $=0.91 \mathrm{C} \quad$ TRP VALOE $=1.23690$

MOAIFIED SNIDON VALUFS

\begin{tabular}{|c|c|c|c|c|c|c|c|c|c|c|c|c|c|c|c|c|c|}
\hline 17 & $\begin{array}{l}31 \\
01\end{array}$ & $\begin{array}{ll}0.10 \text { ค9F } & 01 \\
0.5857 \mathrm{E} & 00\end{array}$ & $\begin{array}{l}0.1037 \mathrm{E} \\
0.53 \mathrm{C5}\end{array}$ & $\begin{array}{l}01 \\
01\end{array}$ & $\begin{array}{l}.0908 E \\
.48328\end{array}$ & $\begin{array}{l}00 \\
00\end{array}$ & $\begin{array}{l}0.0395 \mathrm{E} \\
0.4349 \mathrm{E}\end{array}$ & 00 & $\begin{array}{r}.8986 \mathrm{R} \\
.3874 \mathrm{R}\end{array}$ & $\begin{array}{l}00 \\
00\end{array}$ & $\begin{array}{l}0.8515 E \\
0.3406 E\end{array}$ & $\begin{array}{l}00 \\
00\end{array}$ & $\begin{array}{l}0.79958 \\
0.29738\end{array}$ & $\begin{array}{l}n 0 \\
00\end{array}$ & $\begin{array}{l}0.74018 \\
0.25558\end{array}$ & $\begin{array}{l}00 \\
00\end{array}$ & $\begin{array}{l}0.6905 \mathrm{E} \\
0.2095 \mathrm{E}\end{array}$ \\
\hline & & VALUES & & & & & & & & & & & & & & & \\
\hline $\begin{array}{l}0 \\
.79058 \\
1579 E \\
2368 E \\
315 A 8 \\
3947 E \\
47.178 \\
5526 E\end{array}$ & $\begin{array}{ll}0 & 0 \\
0 & 1 \\
0 & 1 \\
0 & 1 \\
0 & 1 \\
0 & 1 \\
0 & 1 \\
0 & 1\end{array}$ & 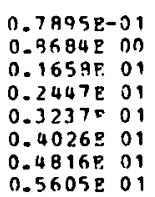 & $\begin{array}{l}0.1579 \mathrm{P} \\
0.74748 \\
0.17270 \\
0.2526 \mathrm{E} \\
0.33160 \\
0.4105 \mathrm{E} \\
0.4995 \mathrm{P} \\
0.5684 \mathrm{E}\end{array}$ & $\begin{array}{ll}0 & 1 \\
0 & 1 \\
0 & 1 \\
0 & 1 \\
0 & 1 \\
0 & 1\end{array}$ & $\begin{array}{l}0.23638 \\
0.1026 \% \\
0.18168 \\
0.26058 \\
0.33958 \\
0.41848 \\
0.4974 \mathrm{~F} \\
0.57638\end{array}$ & $\begin{array}{ll}0 & 0 \\
0 & 1 \\
0 & 1 \\
0 & 1 \\
0 & 1 \\
0 & 1 \\
0 & 1 \\
0 & 1\end{array}$ & $\begin{array}{l}0.3158 \mathrm{E} \\
0.1105 \mathrm{E} \\
0.1895 \mathrm{E} \\
0.2694 \mathrm{E} \\
0.3474 \mathrm{E} \\
0.4263 \mathrm{E} \\
0.5053 \mathrm{E} \\
0.5942 \mathrm{E}\end{array}$ & $\begin{array}{ll}0 & 1 \\
0 & 1 \\
0 & 1 \\
0 & 1 \\
0 & 1 \\
0 & 1 \\
0 & 1 \\
01 & 1\end{array}$ & $\begin{array}{l}.3947 E \\
.11848 \\
.1974 E \\
.2763 E \\
.3553 E \\
.4342 E \\
.51328 \\
.59218\end{array}$ & $\begin{array}{l}0 \\
0 \\
0 \\
0 \\
0 \\
0\end{array}$ & $\begin{array}{l}.7370 \\
.1363 \mathrm{E} \\
.2053 \mathrm{E} \\
.2842 \mathrm{E} \\
.3632 \mathrm{E} \\
.4421 \mathrm{E} \\
.5211 \mathrm{E} \\
0.6000 \mathrm{~g}\end{array}$ & $\begin{array}{ll}0 & 0 \\
0 & 1 \\
0 & 1 \\
0 & 1 \\
0 & 1 \\
01 & 1 \\
01 & 1 \\
0 & 1\end{array}$ & $\begin{array}{l}0.5526 \mathrm{E} \\
0.1342 \mathrm{E} \\
0.2132 \mathrm{P} \\
0.2929 \mathrm{E} \\
0.37118 \\
0.4500 \mathrm{E} \\
0.5289 \mathrm{E} \\
0.6079 \mathrm{E}\end{array}$ & $\begin{array}{ll}3 & 0 \\
0 & 1 \\
0 & 1 \\
1 & 1 \\
0 & 1 \\
0 & 1 \\
0 & 1 \\
0 & 1\end{array}$ & $\begin{array}{l}.6316 \mathrm{E} \\
.1421 \mathrm{E} \\
.22118 \\
.3000 \mathrm{E} \\
.3789 \mathrm{P} \\
.4579 \mathrm{E} \\
.536 \mathrm{BE} \\
.615 \mathrm{AP}\end{array}$ & $\begin{array}{l}n 0 \\
1 \\
01 \\
01 \\
01 \\
01 \\
01 \\
01 \\
01\end{array}$ & $\begin{array}{l}0.7105 \mathrm{~B} \\
0.1500 \mathrm{E} \\
0.22898 \\
0.3079 \mathrm{E} \\
0.3868 \mathrm{E} \\
0.46580 \\
0.54478 \\
0.6237 \mathrm{~g}\end{array}$ \\
\hline
\end{tabular}

EN (I) VALIES

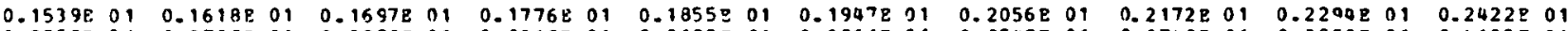

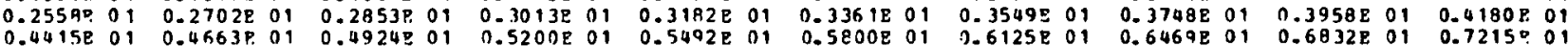
$0.0999010 .52002010 .5492 \mathrm{E} 01$

PS (J) VALUES

$0.24011 \mathrm{E}-010.23100 \mathrm{E}-010.22175 \mathrm{P}-010.21074 \mathrm{E}-010.19846 \mathrm{E}-010.18520 \mathrm{P}-010.17110 \mathrm{E}-010.15784 \mathrm{~B}-010.14352 \mathrm{P}-010.13066 \mathrm{P}-01$

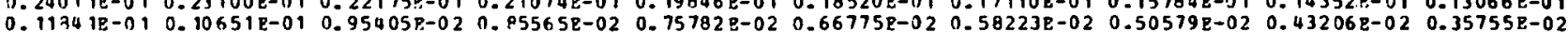

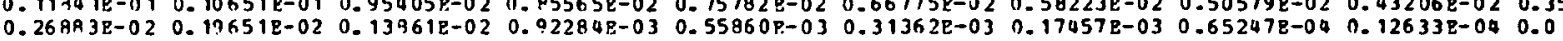

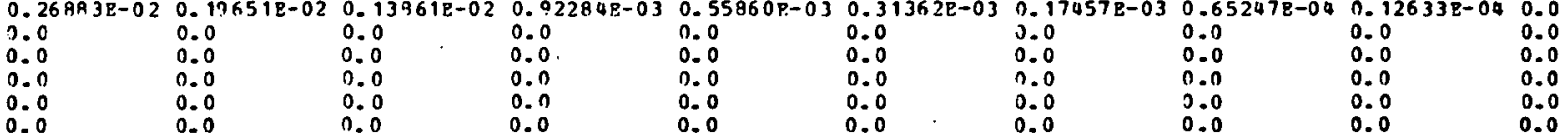

zS (J) VALOES

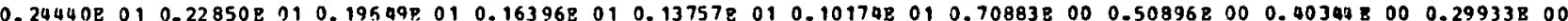

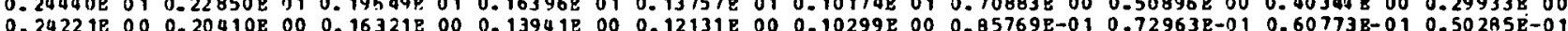

\begin{tabular}{|c|c|c|c|c|c|c|c|c|c|}
\hline $\begin{array}{l}409508-0 \\
0 \\
0 \\
0 \\
0 \\
0\end{array}$ & $\begin{array}{l}0.32 \text { B35E-0 } \\
0.0 \\
0.0 \\
0.0 \\
0.0 \\
0.0\end{array}$ & $\begin{array}{l}0.252538-01 \\
0.0 \\
0.0 \\
0.0 \\
0.0 \\
0.0\end{array}$ & $\begin{array}{l}0.19073 \mathrm{~B}-01 \\
0.0 \\
0.0 \\
0.0 \\
0.0 \\
0.0\end{array}$ & $\begin{array}{l}0.12520 \mathrm{z}-01 \\
0.0 \\
0.0 \\
0.0 \\
0.0 \\
0.0\end{array}$ & $\begin{array}{l}0.80752 E-02 \\
0.0 \\
0.0 \\
0.0 \\
0.0 \\
0.0\end{array}$ & $\begin{array}{l}0.449748-02 \\
0.0 \\
0.0 \\
0.0 \\
0.0 \\
0.0\end{array}$ & $\begin{array}{l}0.19 \\
0.0 \\
0.0 \\
0.0 \\
0.0 \\
0.0\end{array}$ & $\begin{array}{l}370 \mathrm{E}-02 \\
\text {, }\end{array}$ & $\begin{array}{l}0.43276 \mathrm{E}-03 \\
0.0 \\
0.0 \\
0.0 \\
0.0 \\
0.0\end{array}$ \\
\hline
\end{tabular}

Fig. 5. Cont'd 
OUTPOT OP SPP.C IS

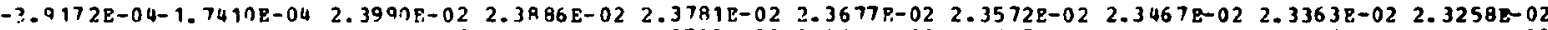

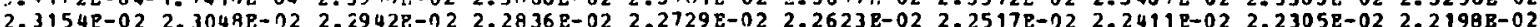
$2.20768-02$ 2-1050E-02 2.1923E-02 2.1697P-02 2.1571P-02 2.1444E-02 2.1318E-02 2-11918-02 2-10648-02 2.09238-02

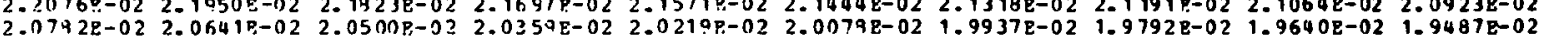
$2.9782-02$ 2. $1.935 \mathrm{E}-02$ 1.963

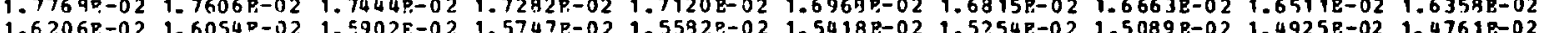

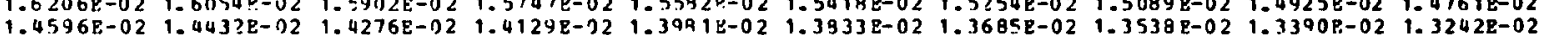

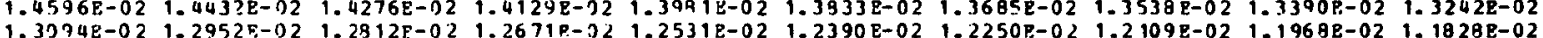

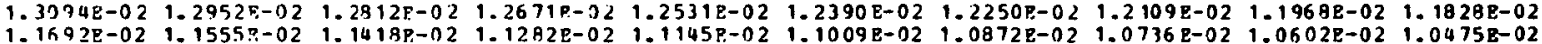
$1.0347 E-02 \quad 1.0220 \mathrm{E}-02 \quad 1.0092 \mathrm{E}-02 \quad 9.9647 \mathrm{E}-03$ 9.8372P-03 $9.7096 \mathrm{E}-039.5921 \mathrm{E}-03 \quad 9.4644 \mathrm{R}-039.3514 \mathrm{R}-03 \quad 9.2385 \mathrm{E}-03$

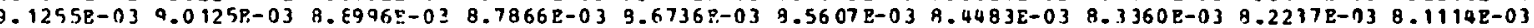
$7.9991 \mathrm{E}-03 \quad 7.3868 \mathrm{P}-03 \quad 7.7745 \mathrm{E}-03 \quad 7.6621 \mathrm{E}-03 \quad 7.5521 \mathrm{P}-03 \quad 7.4487 \mathrm{E}-03$ 7. $3453 \mathrm{E}-03 \quad 7.2419 \mathrm{E}-03 \quad 7.1395 \mathrm{E}-03 \quad 7.0351 \mathrm{E}-03$

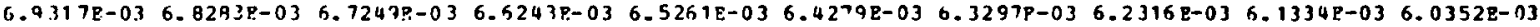

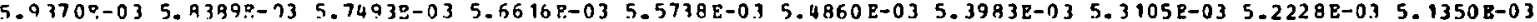

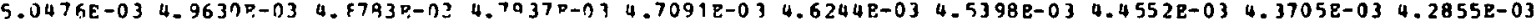

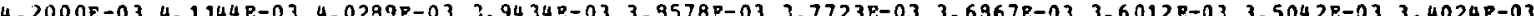
$30058-033.19869-033.09698-032.99498-032.09318-032.79128-032.68948-032.60618-032.52318-032.94018-03$ (1)

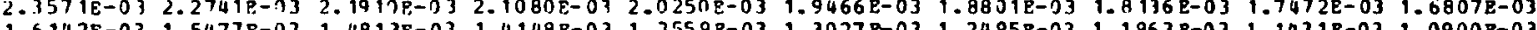
. $1.9368 E-03$ 9. A3508-04 9.304n:-04 8.

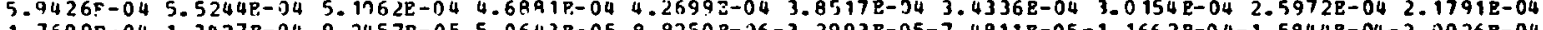

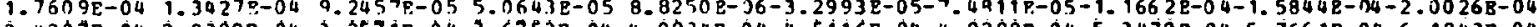
$-2.4207 \mathrm{E}-04-2-838^{\circ} \mathrm{E}-04-3.2571 \mathrm{E}-04-3.6753 \mathrm{E}-04-4.0934 \mathrm{E}-04-4.5116 \mathrm{E}-04-4.9298 \mathrm{E}-04-5.3479 \mathrm{E}-04-5.7661 \mathrm{E}-04-6.1843 \mathrm{E}-04$ $-6.5024 E-04-7.0206 P-04-7.438 B E-04-7.0569 E-04-8.2751 E-04-9.69338-04-9.11148-04-9.5296 E-04-9.9477 E-04-1.0366 E-03$ $-1.1794 \mathrm{E}-03-1.1202 \mathrm{~g}-0.3-1.1620 \mathrm{P}-03-1.203 ? \mathrm{P}-03-1.2457 \mathrm{z}-03$

1760. 4744. 12767. 47623.445809. 854610.713035. 559905. 517645.1021071.

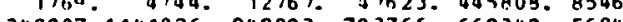
. 351262 . 20428. 209152. 196135. 183032 . 171214. 159866.152089 .145527 .139151 .1323090125578 $107130.102234 .67060^{\circ}, 32420^{\circ} 98965^{\circ} 84920^{\circ} 71942,78412,76093.73688^{\circ}$ $71901.69549 .67063 .64899 .53159 .6070005859 .5648 .55071 .5267 \%$

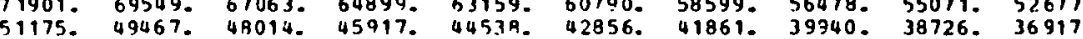
35689 . 34075. 33309. 32256. 31124. 30035. 29133. 28385. 27215. 26365 25466. 24R81. 24015. 23060. 22404. 21860. 21404. 20792. 20222. 19605. 19268. 190A1. 18217. 17608. 17448. 16803. 16245. 15703. 15272. 14821. 14391. 14.37. 13431. 13331. 12947. 12576. 12173. 11734. 11251. 10873. 10618.90403 .90039 .9679 .9471 .9208 .9880 .9844 .8362 .9140$. 5999. 5687. 5631. 5455. 5243. 5113. 5013. 4796. 4720. 4651. 4501. 4306. 4155. 4110.4022. 3838. 3671. 3482. 3525. 3321. 3329. 3251. 3113. 2989. 2905. 2814. 2688. 2599. 2494. 2013. 2382. 225.3. 2151. 2038. 2032. 1959. 1845. 1820. 1747.

1682.1616 .1448 .1434 .1397$.

$11,0$.

792- 784.

314.2505.

183. 147.

35.23.

I IU4. $11<0$.

439.473 .049 .627$.

253.289 .249 .230$.

141. 132

6ก. 51. 53.50.

1359.

प11. पा1

599.583.

375 .

194.

102.

179.

91.

1284. 1239.

850.
547.

345. 325.

77. 69.

20. 26. 1A.

JACH'SROUND COUHT

EXPERTMENT HUMBER 1459A

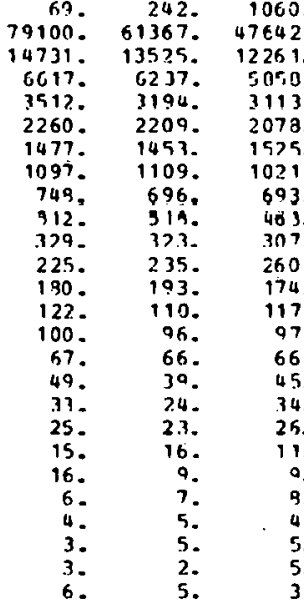

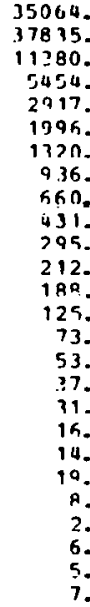

G1521. 30344. 31050.25591. 10587 .

5144.

2796.

2004 .

1265.

962 .

529.

is 37 .

250.

165 .

115.

63.

58.

77

22.

13.

$\circ$.

8.

4.

\section{7.}

4814.

1930.

1241.

885 .

613.

394.

210.

159.

10.5.

61.

43.

10.

9.

6.

i.

43796. 170418. 143012. 104954. 20350. 19485. 17856. 16237.

$9127.8370, \quad 7772.7233$.

2599. 2427. 2484. 2301.

1811.1718 .01646 .1587$.

1317.1170 .1171 .1057$.

561. 860.0787 .0812$.

$363.537 .0149 . \quad 566$.

288. 224. 243.

$185 . \quad 774 . \quad 204 . \quad 202$.

134. 129. $150 . \quad 138$.

73. Ba. 74. 5R.

52.53 .55

42.

21. 16.

11.14.

3. 10.

6.

3.

Fig. 5. Cont'd 
RESOLTS FROA SUBBONTLNE VSHTH

1769. 4744. 12767. 47623. 445909. 854610. 713035.558905. 517645.1021071. 1348907.1141026 . 949893. 793766. 669342. S6A48B. 510626. 456947. 410371. 371929.

340986. 315994. 295384. 277516. 261765. 247403. 233971. 221129. 208675. 196577.

184965. 174060. 164064. 155063. 146990. 139676. 132950. 126721. 121011. 115378.

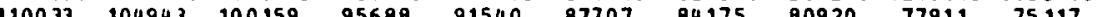

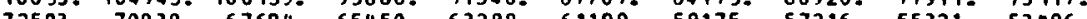

$5 \times 216.55321 .53496$.

51728. 50063. 48393. 46770. 45193. 43652. 42156.40705. 39300. 37943.

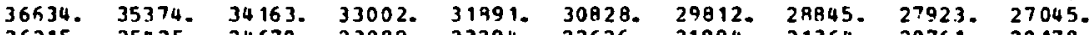

26215.25425 .24670 .23989 .23294 .22626 .21984 .21364 .20761 .20178$.

19613. 19065. 184.32. 18013. 17510. 17019. 16541. 16076. 15622. 15191.

14751. 14334. 13929. 1.3533. 13149. 12791. 12426. 12071. 11726. 11390.

11063.90743 .910432 .9131 .9837 .9553 .9276 .9008 .9749 .849$.

A253. 8017. 7789. 7568. 7354. 7147. 6945. 6761. 6571. 6386.

4647. 4512. 4381. 4255. 4131. 4011. 3894. 3780. 3670. 3568.

3463. 3360. 3260. 3162. 3067. 2975. 2985. 2736. 2710. 2626

2544.2465 .2397 .2312 .2238 .2167 .2098 .2031 .2965 .21901$.

1R39. 1779. 1725. 1669. 1612. 1558. 1505. 1454. 1405. 1356.

1309. 1263. 1219. 1175. 1132. 1091. 1051. 1013. 975. c38.

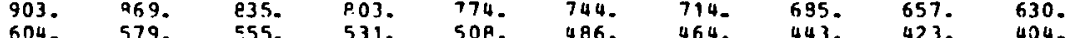

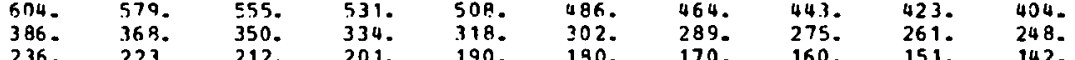

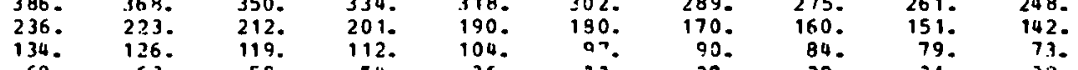

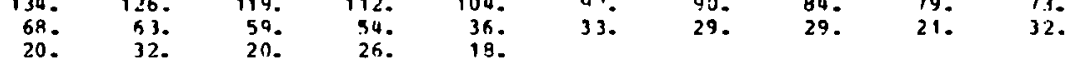

\begin{tabular}{|c|c|c|c|c|c|c|c|c|c|}
\hline $\begin{array}{r}69 . \\
79100 . \\
15199 . \\
6924 . \\
3594 . \\
2291 . \\
1560 . \\
1092 . \\
765 . \\
524 . \\
350 . \\
249 . \\
187 . \\
140 . \\
101 . \\
72 . \\
52 . \\
37 . \\
26 . \\
18 . \\
13 . \\
9 . \\
7 . \\
5 .\end{array}$ & $\begin{array}{r}242 . \\
61367 . \\
13881 . \\
635.3 . \\
3402 . \\
2108 . \\
1505 . \\
1055 . \\
737 . \\
503 . \\
336 . \\
242 . \\
182 . \\
135 . \\
98 . \\
70 . \\
50 . \\
36 . \\
25 . \\
18 . \\
12 . \\
9 . \\
6 . \\
5 . \\
4 .\end{array}$ & $\begin{array}{r}1060 . \\
47642 . \\
12726 . \\
5926 . \\
3226 . \\
2119 . \\
1450 . \\
1019 . \\
711 . \\
483 . \\
324 . \\
230 . \\
176 . \\
131 . \\
94 . \\
69 . \\
49 . \\
35 . \\
24 . \\
17 . \\
12 . \\
9 . \\
6 . \\
5 . \\
4 . \\
3 .\end{array}$ & $\begin{array}{r}35064 . \\
37835 . \\
11703 . \\
5533 . \\
3066 . \\
2041 . \\
1398 . \\
944 . \\
686 . \\
464 . \\
313 . \\
228 . \\
172 . \\
127 . \\
91 . \\
66 . \\
47 . \\
34 . \\
23 . \\
16 . \\
12 . \\
8 . \\
6 .\end{array}$ & $\begin{array}{r}61521 . \\
31050 . \\
10790 . \\
5170 . \\
2920 . \\
1966 . \\
1349 . \\
950 . \\
661 . \\
445 . \\
302 . \\
221 . \\
167 . \\
123 . \\
88 . \\
63 . \\
45 . \\
32 . \\
23 . \\
16 . \\
11 . \\
8 . \\
6 . \\
5 .\end{array}$ & $\begin{array}{l}39344 . \\
25591 . \\
9969 . \\
4835 . \\
2789 . \\
1893 . \\
1301 . \\
917 . \\
636 . \\
428 . \\
292 . \\
215 . \\
162 . \\
119 . \\
65 . \\
61 . \\
44 . \\
31 . \\
22 . \\
15 . \\
11 . \\
8 . \\
6 . \\
4 . \\
1 .\end{array}$ & $\begin{array}{r}49796 . \\
23024 . \\
9222 . \\
4529 . \\
2669 . \\
1821 . \\
1256 . \\
835 . \\
613 . \\
410 . \\
283 . \\
209 . \\
157 . \\
115 . \\
83 . \\
59 . \\
42 . \\
30 . \\
21 . \\
15 . \\
10 . \\
9 .\end{array}$ & $\begin{array}{r}170418 . \\
20633 . \\
8539 . \\
4258 . \\
2560 . \\
1751 . \\
1212 . \\
854 . \\
589 . \\
394 . \\
274 . \\
203 . \\
153 . \\
112 . \\
80 . \\
57 . \\
41 . \\
29 . \\
20 . \\
14 . \\
10 .\end{array}$ & $\begin{array}{r}43012 . \\
18527 . \\
7913 . \\
4027 . \\
2461 . \\
1684 . \\
1171 . \\
323 . \\
567 . \\
379 . \\
265 . \\
197 . \\
148 . \\
108 . \\
77 . \\
56 . \\
40 . \\
28 . \\
20 . \\
14 . \\
10 .\end{array}$ & $\begin{array}{r}104854- \\
16729 \\
7342- \\
3801 . \\
2368 . \\
1621 . \\
1131 . \\
794 . \\
545 . \\
364- \\
257 . \\
192- \\
144 . \\
104 . \\
75 . \\
54 . \\
38 . \\
27 . \\
19 . \\
13 .\end{array}$ \\
\hline
\end{tabular}

SHOOTHED FOREGRODND MINOS BACKGROURD

1591. 4120. 10036.

0. 287278. 755804. 584719. 119764, 149125.750879. 1145078. 982893. 827127. 696271. 599331. 502544. 451296. 403780 . 362631. 328822. 301920 . 280235. 363493. 397359. 3.3960. 231715. 210207. 107125. 188284. 177657. 167381 . 157689. 149795. 140806. 133667. 127217. 121279.115748. 110633. 105584. 100772. 96179. 91846. B7788. 84014. B0521. 77297. 74322. 71571. 69015. 6018905822256322 . 54483,52704.50981.49320. 47709 . 46184. 44656. 43167. 41717. 40299. 38921. 37581. 36283. 35C29.

33819 32654, 31537, 30466, 29442, 29464. 27532.26645. 25801.25000.

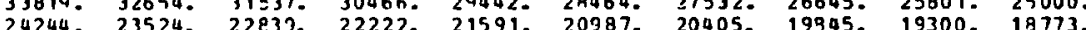

14647. 14244.

12729, 12371. 12038. 11698. 11367. 11043. 10729.

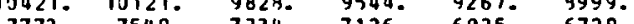

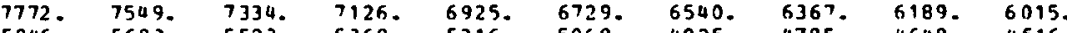

5846. 5682. 5523. 5363. 5216. 5068. 4925. 4785. 464月. 4516.

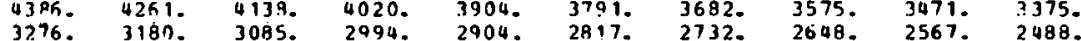

2411.2335 .2262 .2191 .2121 .2054 .21988 .1925 .1963 .903$.

1744. 1687. 1635. 1581. 1529. 1478. 1428. 1379. 1332. 1286.

1247. 110R. 1159- 1114. 1174. $1175, \quad 997.960 .924=990$.

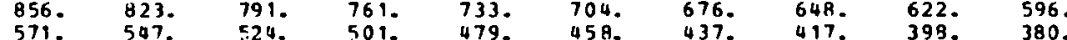

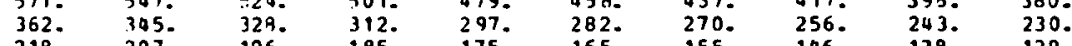

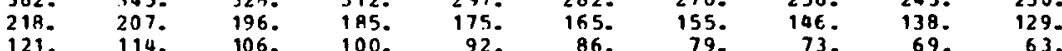

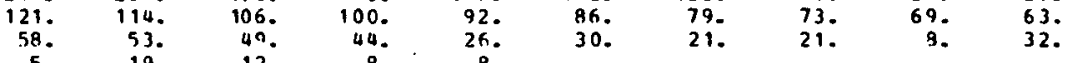

Fig. 5. Cont'd 
MIGH EHDRGY PULSE HEIGHTS TO BE SUATRACTED

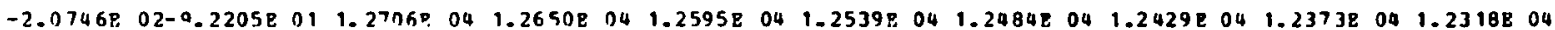

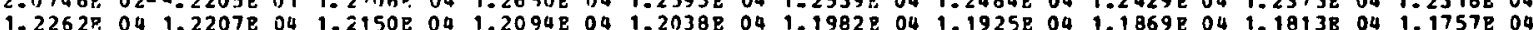

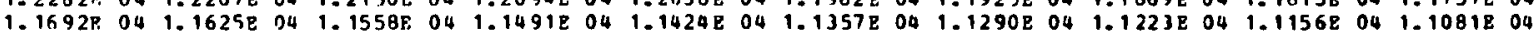

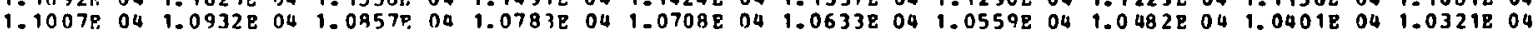

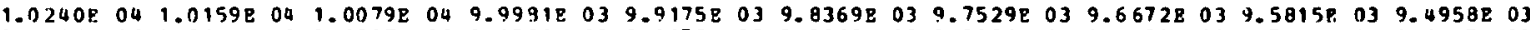

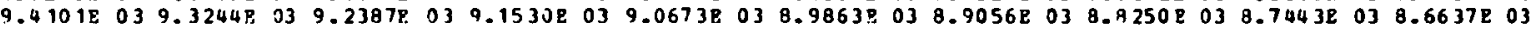

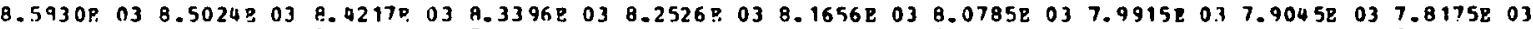
$\begin{array}{llllllllllllllllllllllll}7.7305 E & 03 & 7.6434 \mathrm{E} & 03 & 7.5609 \mathrm{E} & 03 & 7.4227 \mathrm{E} & 03 & 7.4045 \mathrm{E} & 03 & 7.3262 \mathrm{E} & 03 & 7.2480 \mathrm{E} & 03 & 7.1697 \mathrm{E} & 03 & 7.0915 \mathrm{E} & 03 & 7.0132 \mathrm{E} & 03\end{array}$

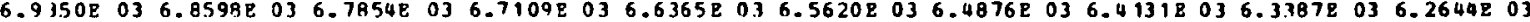

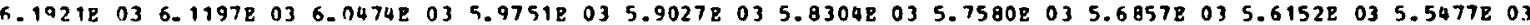

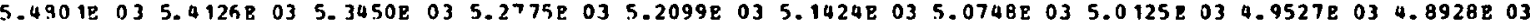

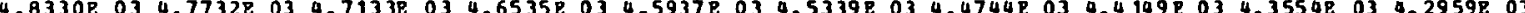

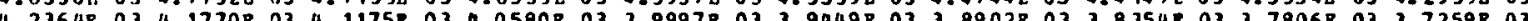
4.23648 (4) (6) $3.14438033 .0923 E$ OJ 3.04498032 .99858032 .95208032 .90558032 .85908032 .81258032 .76618032 .7196203

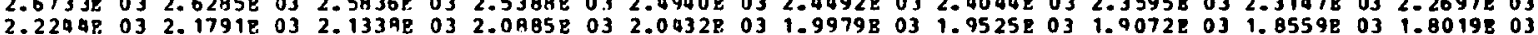

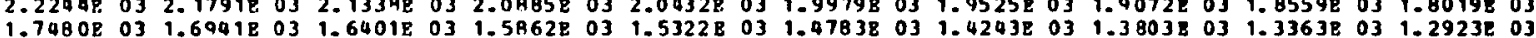

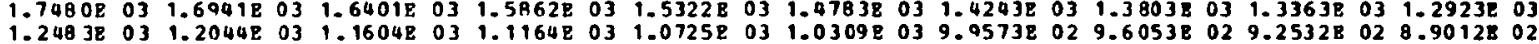

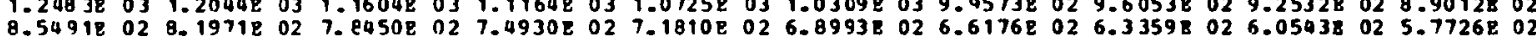

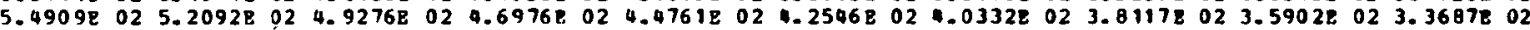

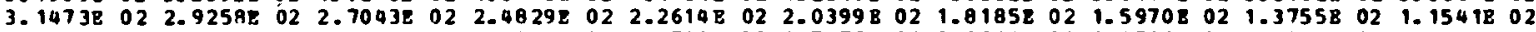
9.32618 $017.1114 \mathrm{E}$ 04 4.8966E 01 2.6P21E 01 4-6738F 00-1.7473E 01-3.9621E 01-6.1766E 01-A.39148 01-1.0606E 02 -1.28218 02-1.5035E 02-1.7250F 02-1.9465E 02-2.1679 E 02-2.3894E 02-2.6109E 02-2.8323E 02-3.053BE 02-3.2753E 02 -3.49678 02-3.7182E 02-3.9397E 02-4.16128 02-4-38268 02-4.60418 02-4.8256E 02-5.04708 02-5.2685B 02-5.49008 02

$-5.7114 \mathrm{E} 02-5.9329 \mathrm{E} 02-6.1544 \mathrm{E} 02-6.3758702-6.5973 \mathrm{R} 02$

MOABALI STYG PACTOR = 5. 3762. OS

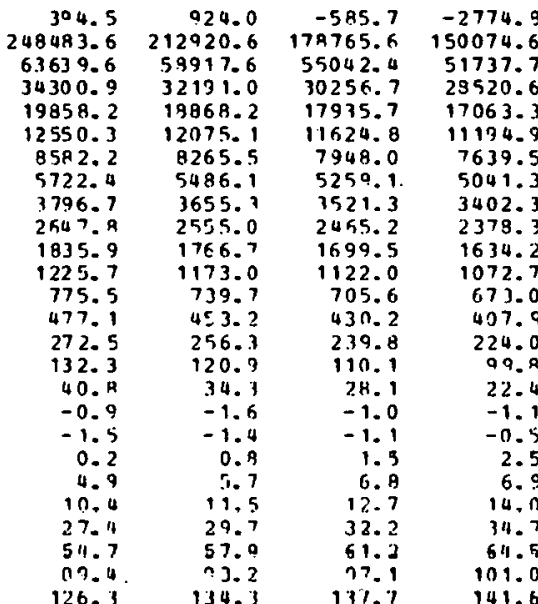

$\begin{array}{rrr}60251.9 & 163035.4 & 125519.9 \\ 126629.6 & 107605.1 & 96376.3 \\ 48813.3 & 46142.2 & 43632.5 \\ 26971.2 & 25572.8 & 24286.5 \\ 16253.2 & 15504.6 & 14815.7 \\ 10782.0 & 10393.0 & 9997.4 \\ 7340.5 & 7048.6 & 6765.2 \\ 4833.9 & 4636.5 & 4449.3 \\ 3280.4 & 3164.0 & 3052.9 \\ 2294.2 & 2212.5 & 2133.2 \\ 1570.9 & 1512.5 & 1452.8 \\ 1025.2 & 579.4 & 935.2 \\ 641.5 & 610.8 & 581.3 \\ 386.0 & 365.0 & 344.9 \\ 208.9 & 194.3 & 180.4 \\ 90.9 & 80.6 & 71.8 \\ 17.1 & 12.3 & 7.9 \\ -0.9 & -0.2 & 0.7 \\ 0.3 & 0.9 & 7.9 \\ 3.3 & 3.1 & 3.1 \\ 6.9 & 7.1 & 7.4 \\ 15.5 & 17.2 & 19.3 \\ 37.3 & 110.0 & 42.8 \\ 67.9 & 71.9 & 71.7 \\ 101.0 & 107.7 & 110.7 \\ & & \end{array}$

$\begin{array}{rrr}23544.1 & 29996.6 & 162003.7 \\ 85965.9 & 75952.1 & 69548.5 \\ 41216.4 & 38853.1 & 36538.5 \\ 23090.2 & 21985.8 & 20896.0 \\ 14182.0 & 13597.4 & 13055.6 \\ 9624.9 & 9264.6 & 8918.0 \\ 6490.6 & 6224.9 & 5969.8 \\ 4271.9 & 4104.0 & 3945.4 \\ 2946.4 & 2843.2 & 2743.9 \\ 2056.3 & 1991.1 & 1907.5 \\ 1393.8 & 1336.0 & 1280.0 \\ 892.8 & 852.0 & 813.0 \\ 595.9 & 528.2 & 502.1 \\ 325.6 & 307.1 & 289.4 \\ 167.2 & 154.6 & 143.8 \\ 63.3 & 55.3 & 47.8 \\ 3.8 & 1.5 & 0.1 \\ -0.2 & -0.9 & -1.3 \\ -0.1 & -0.2 & -0.1 \\ 3.3 & 3.6 & 4.1 \\ 7.9 & 8.6 & 9.4 \\ 21.2 & 23.1 & 25.2 \\ 45.6 & 49.6 & 51.6 \\ 79.2 & 83.1 & 05.6 \\ 115.4 & 117.3 & 127.4\end{array}$

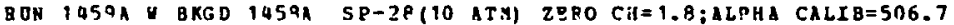

BBIAS=-2.90 CKAMMPLS: 255 . SHDOTH= 1. BOTTOM EYPRGY = 0.3400 AEV

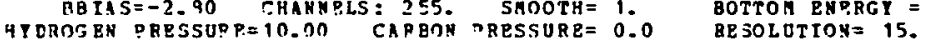

GROTPED SPECTRUN OP SLOPPS PEE MONITOR COUHT

ADYITOR TOONT: 503 .

\begin{tabular}{rrrr}
$\begin{array}{r}\text { INDICATED } \\
\text { CHANYEL }\end{array}$ & \multicolumn{2}{c}{$\begin{array}{c}\text { ESERGY } \\
\text { BOII NDAPY }\end{array}$} \\
36 & 41 & 0.2964 & $0.350 A$ \\
42 & 47 & 0.3508 & 0.4051 \\
48 & 55 & 0.4051 & 0.4776 \\
56 & 65 & 0.4776 & 0.5693 \\
66 & 76 & 0.5683 & 0.6680 \\
77 & 00 & 0.6690 & 0.7767 \\
89 & 104 & 0.7767 & 0.9219 \\
105 & 127 & 0.0219 & 1.0849 \\
123 & 143 & 1.0849 & 1.2752 \\
144 & 167 & 1.2752 & 1.4927
\end{tabular}

$\begin{array}{ll}1.0849 & 1.2752 \\ 1.2752 & 1.4927\end{array}$

MID
ENEPGY
0.3236
0.377 .9
0.4414
0.5230
0.6191
0.7224
0.8492
1.0033
1.1801
1.3840

SIGHA

7.71

7.12
6.58

6.58
6.02

5.51

5.07

4.65

4.25

3.89
3.57
GROOPED

6897.820 4864.189 3901.771 3380.144 2653.002 1636.105 1286.914 882.818 486.627 224.640

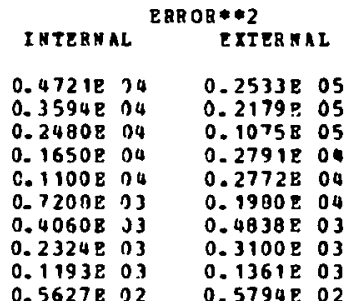

Fig. 5. Cont'd 


\begin{tabular}{|c|c|c|c|c|}
\hline \multicolumn{2}{|c|}{$\begin{array}{l}\text { BNERGY } \\
\text { BOUNDARY }\end{array}$} & $\begin{array}{l}\text { PLUX } \\
\text { GRONP }\end{array}$ & & $\underset{\operatorname{PEV}}{\operatorname{PLDX}}$ \\
\hline $\begin{array}{l}0.2964 \\
0.3508 \\
0.4051 \\
0.4776 \\
0.5683 \\
0.5680 \\
0.7767 \\
0.9219 \\
1.0749 \\
1.2752\end{array}$ & $\begin{array}{l}0.3508 \\
0.4051 \\
0.4776 \\
0.5683 \\
0.6680 \\
0.7767 \\
0.9218 \\
1.0849 \\
1.2752 \\
1.4927\end{array}$ & $\begin{array}{l}1.1440 \mathrm{E} \\
1.0195 \mathrm{E} \\
1.0054 \mathrm{E} \\
1.1489 \mathrm{E} \\
1.2173 \mathrm{E} \\
9.5383 \mathrm{E} \\
9.9922 \mathrm{E} \\
1.0103 \mathrm{E} \\
9.3099 \mathrm{E} \\
7.0436 \mathrm{E}\end{array}$ & $\begin{array}{l}04 \\
04 \\
04 \\
04 \\
04 \\
03 \\
03 \\
04 \\
03 \\
03\end{array}$ & 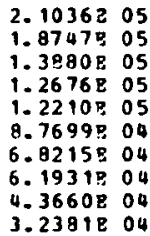 \\
\hline
\end{tabular}

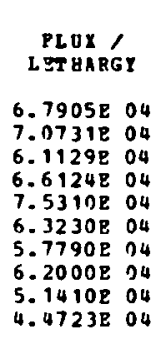

$04-04-80$

SUMnen $P$ LUX $x=$

D. 1002 F. 06

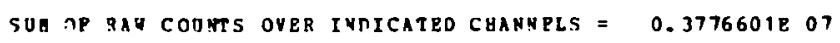

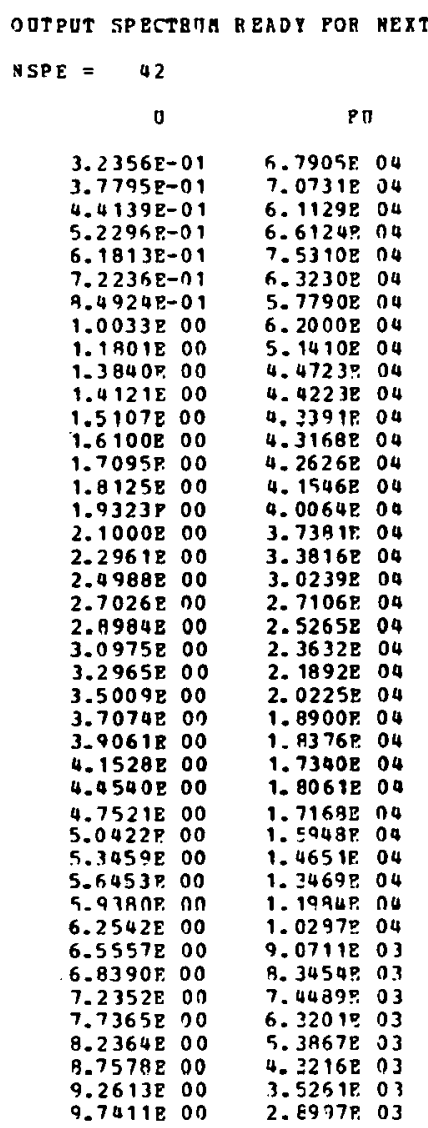

$\star \star \star N O T E:$ The preceding output is repeated for the $3 \mathrm{~atm}$ and $1 \mathrm{~atm}$ detectors

Fig. 5. Cont'd 
RINS 1459A (BRGD 1459A), SF-22(10 ATM): 1460A (BKGD 1460B), SP-26 (3 ATA):

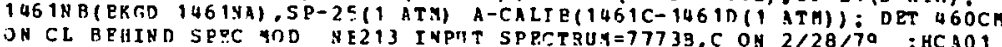

N

FIPRGY QกII YกA १Y (MEv)

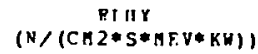

(2ERCEM

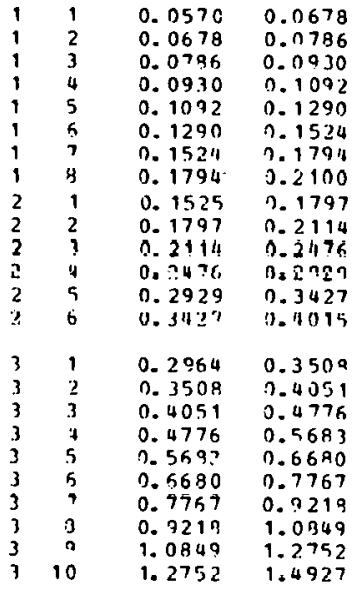

\begin{tabular}{|c|c|c|}
\hline $\begin{array}{l}9.83798 \\
8.10678 \\
4.5769: \\
2.72698 \\
4.49598 \\
3.72368 \\
2.19762 \\
2.39158\end{array}$ & $\begin{array}{l}05 \\
05 \\
05 \\
05 \\
05 \\
05 \\
05 \\
05\end{array}$ & $\begin{array}{l}1.76 \\
1.94 \\
2.96 \\
4.97 \\
2.71 \\
3.01 \\
4.91 \\
4.45\end{array}$ \\
\hline $\begin{array}{l}2.1774 \mathrm{E} \\
2.2900 \mathrm{~F} \\
3.36128 \\
2.90267 \\
2.2640 \mathrm{~F} \\
1.92339\end{array}$ & $\begin{array}{l}95 \\
05 \\
05 \\
05 \\
05 \\
05\end{array}$ & $\begin{array}{l}2.24 \\
2.08 \\
1.98 \\
1.94 \\
1.78 \\
1.90\end{array}$ \\
\hline $\begin{array}{l}2.10368 \\
1.87478 \\
1.78909 \\
1.26768 \\
1.22100 \\
8.76798 \\
6.82158 \\
6.19312 \\
4.36698 \\
3.23918\end{array}$ & $\begin{array}{l}05 \\
05 \\
05 \\
05 \\
05 \\
04 \\
04 \\
04 \\
04 \\
04\end{array}$ & $\begin{array}{l}1.19 \\
1.48 \\
1.59 \\
1.50 \\
1.54 \\
2.111 \\
2.00 \\
2.18 \\
2.74 \\
3.34\end{array}$ \\
\hline
\end{tabular}

DUTPUT SPECTPIIM ORDERED BY ENPBG

$04-04-93$

RIVS 1459 A (BKGD 1459A), SP-29(10 ATM): $1460 \mathrm{~A}$ (3KGD 1460B), SP-26 (3 ATA):

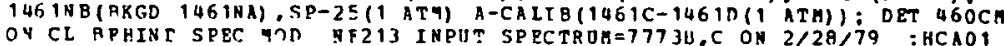

H RNERGT BOUNDATY (I)PV)

1
2
3
4
5

0.0570
0.0679
0.0796
0.0930

0.0930

0.1290

0. 1290

ว. 1524

0.1529
0.1794

0.1794
0.1797

ค. 1524

0.1794

0.1797

0.2100
0.2114

$0.2116 \quad 0.247 x$

ก. $2475 \quad 0.2923$

0.2964

$0.3477 \quad 0.4015$

0. $35 \cap 8 \quad 0.4051$

U. 4051 U.4116

$0.4776 \quad 0.56 \mathrm{A3}$

D. ARA जि KKAO

$0.6680 \quad 0.7767$

$0.7767 \quad 0.9215$

$0.9218 \quad 1.0849$

1. $0849 \quad 1.2752$

1. $2752 \quad 1.4927$

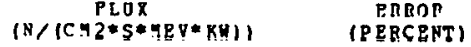

B. $833 \mathrm{AE} 05 \quad 1.75$

Q. Q067D OS

4. $5708 \mathrm{E}$ O5 2.96

$\begin{array}{ll}4.0959 \mathrm{P} 05 & 497 \\ & 2.71\end{array}$

$3.7230209 \quad 3.01$

$2.1996 \% 05 \quad 4.90$

$2.1724505 \quad 2.24$

$\begin{array}{ll}2.3905005 & 4.45 \\ 2.2800905 & 2.09\end{array}$

$2.36 \mathrm{i} 2 \mathrm{03}$

2.90248 05 1.39

$2.2640 ? 05 \quad 1.78$

2. 10036 165

$1.9747805 \quad 1.48$

1.38609 ob 1.54

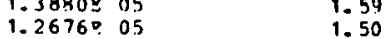

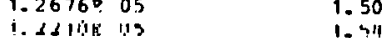

$\begin{array}{ll}\text { i. } 13115 \text { 13 } & 1.311 \\ \text { 8. } 76998 \text { ou } & 2.11\end{array}$

6. 929500402.09

$6.1931804 \quad 2.18$

$\begin{array}{ll}4.3660004 & 2.74 \\ 3.2381504 & 3.34\end{array}$

Fig. 5. Cont'd 
PLOTTI HG COMAENCING

.................

W... DISSPL I TERSTON 7.5 .....

NC. OP FIRST PLOTTOO

PLCF NO. 100 DITH THE TITL

SPECT RUA MODIFIER SHIRLD CONFITURATION

HAS TEEN CCYPLETED.

DLCT ID. READS

PLOT 100 12.54.01 PRI 4 APR, 19PO JOB=JOJPLT1, ORNL DISSPLA FPR 7.5

DATA POR PLOT

PC. nP CURVES DRAWH

HORIZ. ATS LENGTH R.5 IHS.

VRAT. AXIS LENGTH 6.0 INS.

HORIZ. ORIGIN 0.400OB-OI VERT. OPITIN 0.200OE OS

HOBIZ AXTS LOS

CTCLO LENG TH 5.00 INS. $C$ YCLE

-

YERT IXIS ICG

CYCLE LPNGTH 3.53 INS./CYCLE

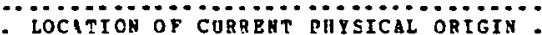

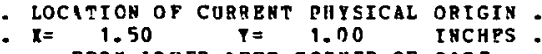

- $T=\begin{gathered}1.50 \\ \text { PROA LONER LEPT CORNER OP PAGR }\end{gathered}$

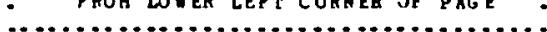

BHD DISSPLA -- 1935 VRCTOBS GEHERATED IR 1 PLOT PBAMES.

Fig. 5. Cont'd 


\section{SPECTRUM MODIFIER SHIELD CONFIGURATION \\ RUNS 1459A.1458A,1460A,1460B,1461NB,1461NA/ \#JOJHCA01}

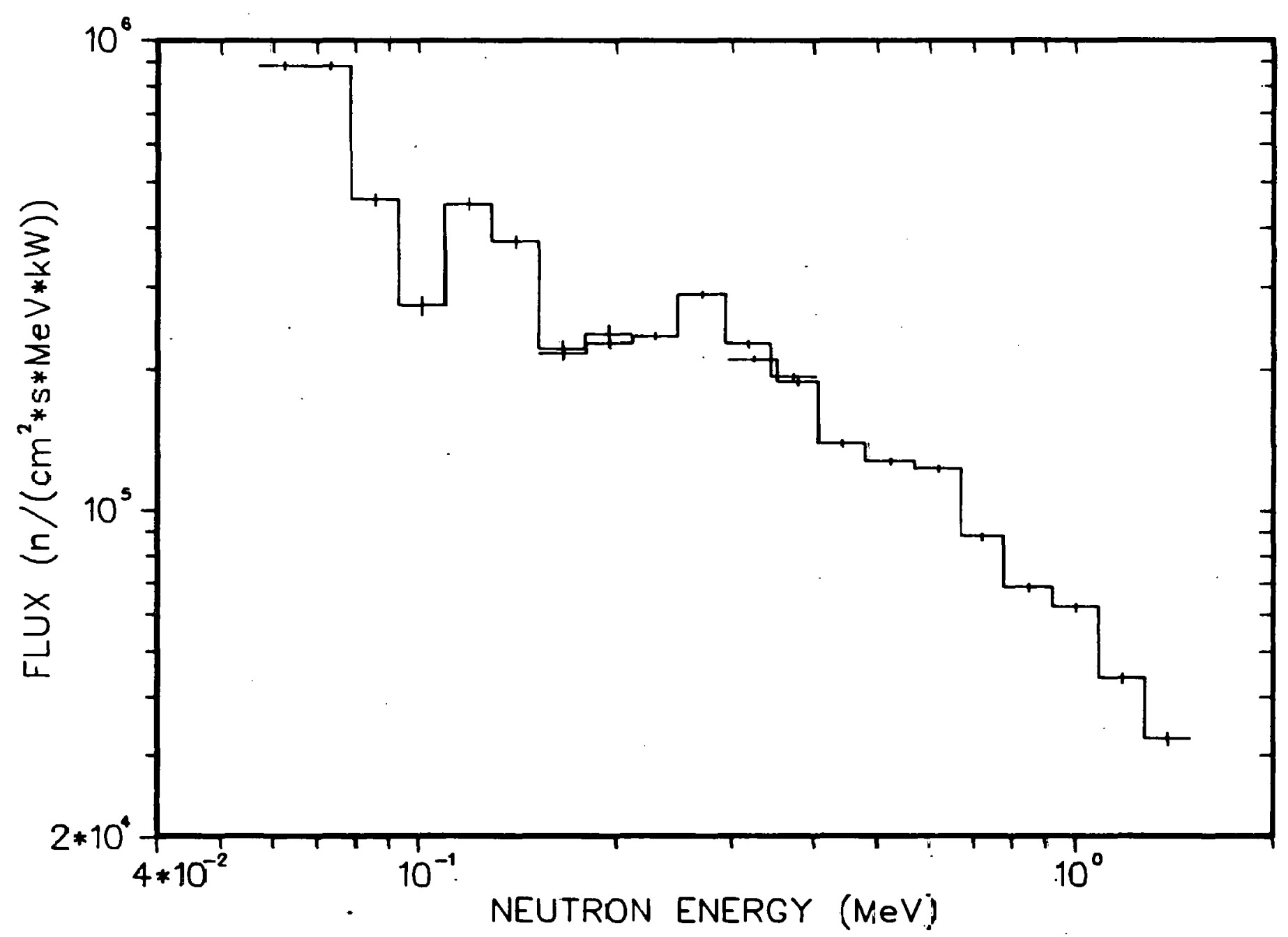

Fig. 6. Final Spectrum Flat from the SPEC-4 Sample Problem. 
Appendix D

Listing of the BENJPLT Program 


$$
\text { D-2 }
$$

THIS PAGE

\section{WAS INTENTIONALLY \\ LEFT BLANK}




\section{D-3}

A source listing of a sample follow-up program for plotting SPEC-4 results is given in Fig. 7. A listing of a sample input is given in Fig. 8, which consists of cards which are punched by SPEC-4, excluding the final two title cards. These titles can be the same ones used as input to the SPEC-4 case. As with RAWDAT (App. B), BENJPLT uses the DISSPLA graphics software and post-processing of the plot data. Besides producing a plot identical to SPEC-4, BENJPLT also prints an edit of the unfolded spectrum in a format identical to the final output of SPEC-4. Therefore, BENJPLT is especially useful for providing publication-quality listings and plots independent of the original SPEC-4 case. 
1 NLINE, IHT 1, IUT2, NC NT, NPMX, NTITL, YLABL, NPT2 DIMENSION IDENT (19)

NCASE $=100$

CALL COMPQS

998 RPAD $(5,501$, END $=999)$ IDENT, NCNT

CALL CONTRL (NCASE)

MEASE $=M C A S R+1$

Go To 998

999 CALL DONEPL

SO 1 FORAAT $(19$ A $4,[4)$

STกP

END

SIJBROUTINE CONTRL (NCASE)

c

CONTRL PERFORHS ALL THE CALLS TO AND FROM TME SUBROUTINES

COMMON / PASS/PAGEX, PAGEY, XPGYOR, YPHYOR, HITE, INA ME, XAXIS, YAXIS,

1 NLINP, IHT1, IHT2, NCNT, NPYX, NTITL, NLABL, HPT2

DIMENS TON $\operatorname{BBD}(60,3), \operatorname{PLX}(6), 3)$, ERPLX $(60,3)$, NPT (3) , TITLE1 (15)

DIME VSION TITLE2 (15),XLABEL (7), YLABEL (7),XVEC (120), YVBC (120)

$\ddot{c}$

SET DEPAULT AND RFAD CONTRCL ?ARAHETERS

$P A: S E X=11 . ?$

RAGEY $Y=9.5$

XP YYO $=1.5$

Y PHYOR $=1.0$

HIT $E=0.18$

INAY $E=100$

$X A X I S=8.5$

YAXIS $=6.0$

NLINE $=2$

IHT $1=-3$

I $\mathrm{TT} 2-2$

IF (NCYT-KO. 0$) \quad \mathrm{NCNT}=3$

NP. $4 X=60$

NTTT T $=15$

$Y L A B L=7$

NPT $2=120$

1 CALL DATRD (EBD, FLX, ERPLX, NPT)

CALL SCALE (EBD,FLX, FRPLX, NPT)

CALL PLTSET (EBD, PLX, BRPLX,NPT, NCASE, TITLE1,TITLE2, XVEC, YVEC)

BSTORN

END

JUDกดUTIN: SCALO (BDD, PLX, BRFLX, HPT)

C SCALE Calculates the minimum ard vaxiqua Values of the INPOT Data

COMMON/PASS/PAG DX, PAGEY, XPUYOR, YPHYOR, HITE, IYM MP, XAXIS, YAXIS,

1 NLIN $E$, IHT1, I HT 2, NC NT, NPMX, NTITL, NLABL, NPU 2

COMYON/LIMIT/XGIN, KMAX, Y. IN, Y MAR

DIMENS ION EBD (NPMX,NCNT), FLX (NPMX,NCNT), ERFLX (NPAX, HCNT)

DINON3TON NPT (NCNT)

XIIX $=0.04$

XMAX $=2.00$

YIIN $=P I X(1,1) *(1.0-E B P L X(1,1) / 100.0)$

Y.:AX $X=\operatorname{PIX}(1,1) *(1.0+\operatorname{ERFI} X(1,1) / 100.0)$

D) $20 K=1, N C N T$

$I I=N P T(K)$

Do $3 \cap, J=1, T, T$,

FRIGH $\operatorname{FIX}(\mathrm{J}, \mathrm{K}) *(1.0+\operatorname{ERFLT}(\mathrm{J}, \mathrm{K}) / 100.0)$

PLON $=F L X(J, K) *(1.0-E R P L X(J, K) / 100.0)$

Fig. 7. Source Listing of the BENJPLT Program. 


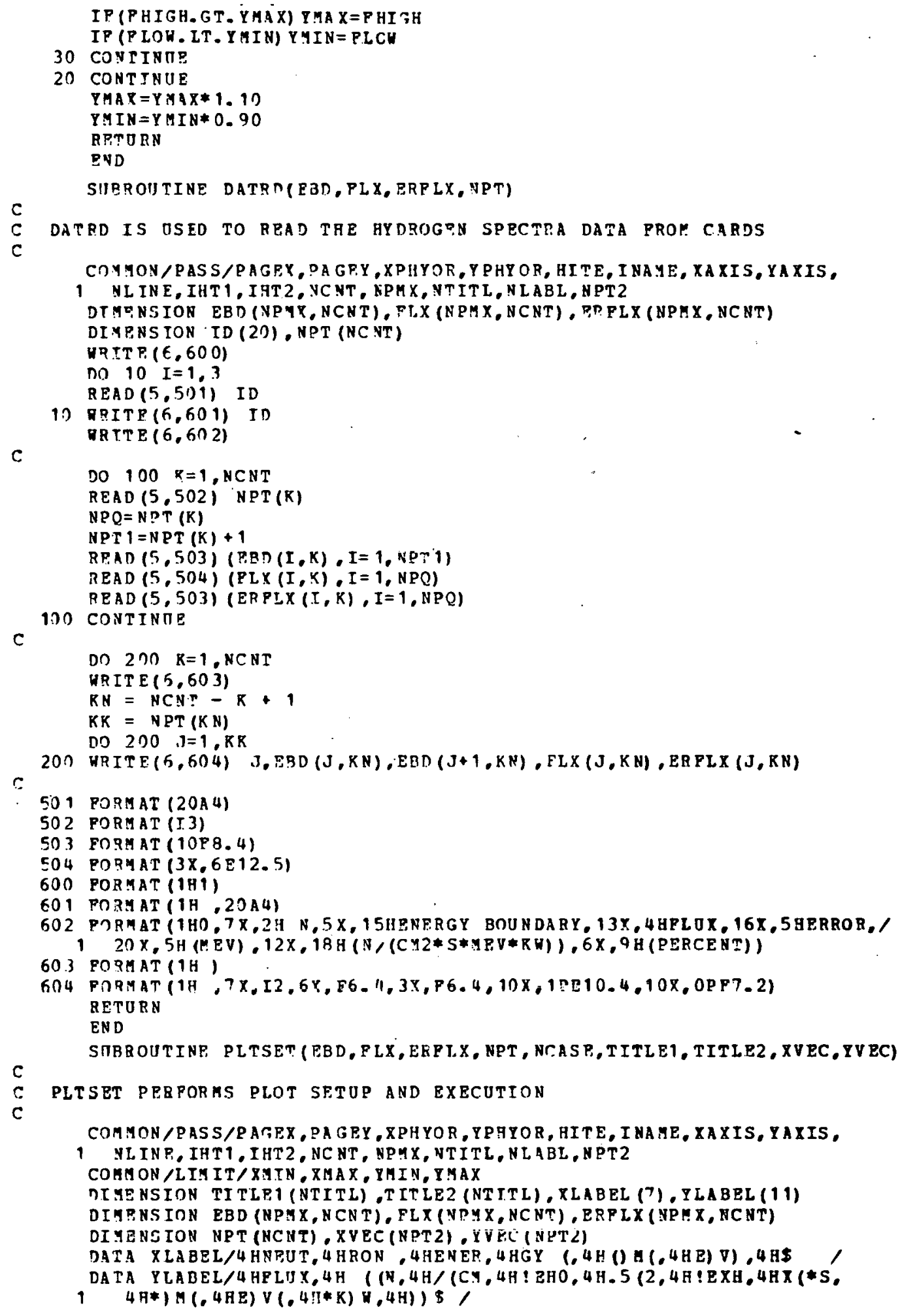

Fig. 7. Cont'd 


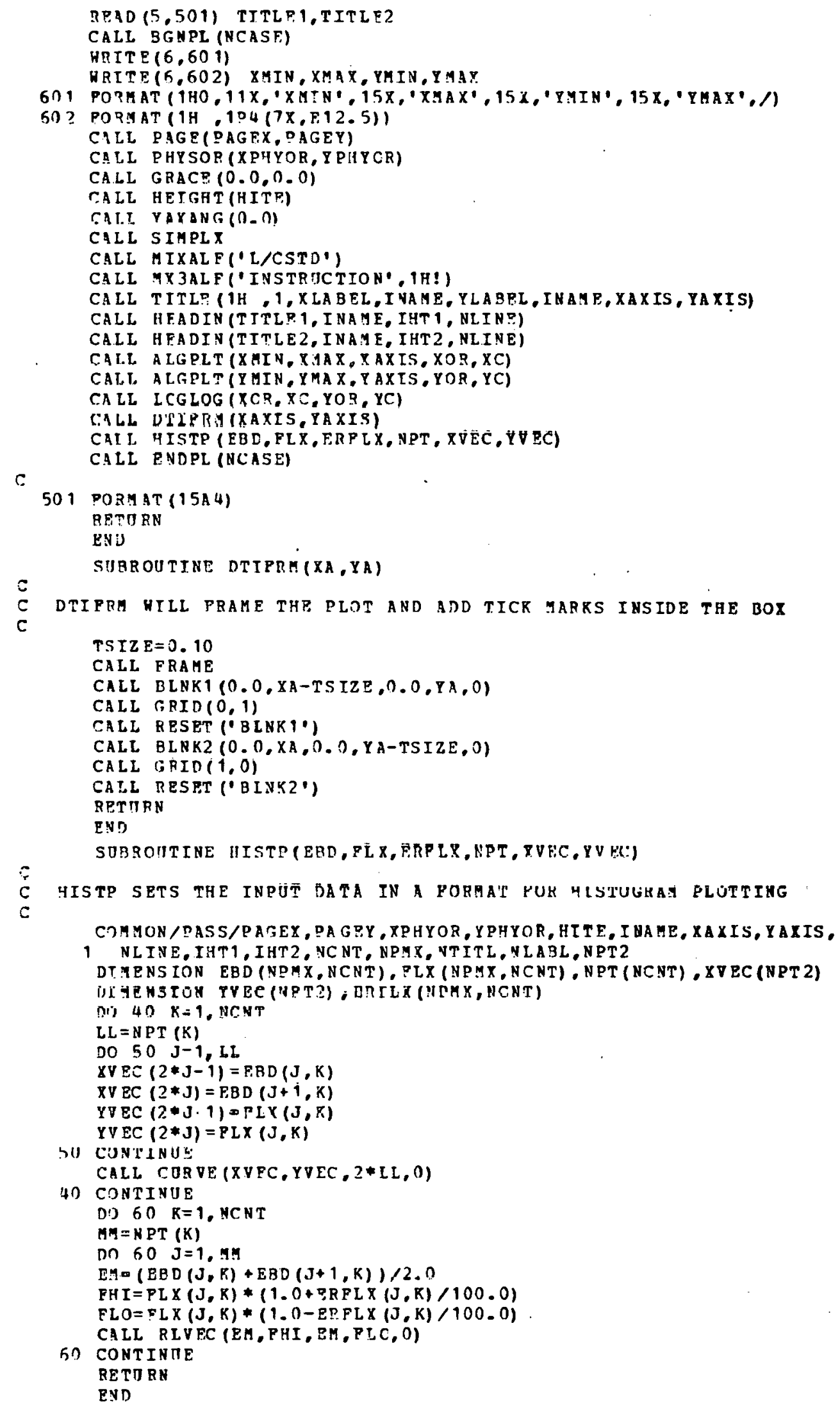

Fig. 7. Cont'd 


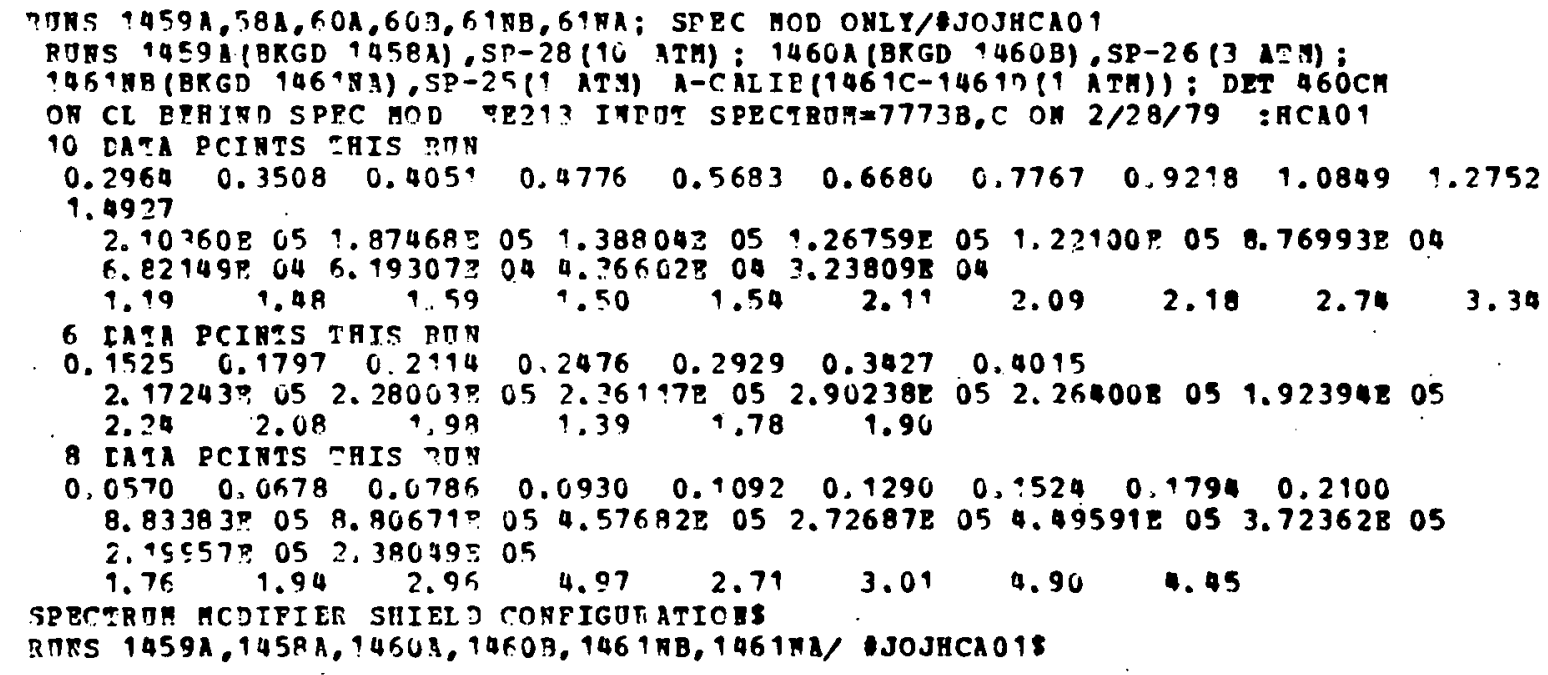

Fig. 8. Listing of Input Needed for BENJPLT. 
ORNL/TM-7384

Distribution Category UC-77

\section{Internal Distribution}

1-2. L. S. Abbott

3. R. G. Alsmiller

4. D. E. Bartine

5. G. T. Chapman

6. J. K. Dickens

7. G. F. Flanagan

8. W. E. Ford

9. U. Gat

10. H. Goldstein (Consultant)

11-15. D. T. Ingersoll

16-20. J. 0. Johnson

21-22. P. R. Kasten

23. R. E. Maerker

24. F. C. Mầienschein

25. J. J. Manning
26. B. F. Maskewitz

27. F. J. Muckenthaler

28. R. W. Peelle

29. R. W. Roussin

30. C. C. Webster

31. C. R. Weisbin

32. P. Greebler (Consultant)

33. W. B. Loewenstein (Consultant)

34. R. Wilson

35-36. Central Research Library

37. $Y-12$ Document Reference Section

38-39. Laboratory Records Dept.

40. Laboratory Records, ORNL RC

41. ORNL Patent Office

\section{External Distribution}

42-43. Director, Division of Reactor Research \& Technology, DOE, Washington, D. C. 20545.

44. Office of Assistant Manager for Energy Research \& Development, DOE-ORO, Oak Ridge, Tennessee 37830.

45-210. For distribuliun as shown in TID-4500 Distribution Category UC-77, Gas-Cooled Reactor Technology. 